\title{
Discovery of Novel $P$. falciparum HDAC1 Inhibitors with Dual-stage Anti-malarial Potency and Improved Safety Based on the Clinical Anticancer Drug Candidate Quisinostat
}

Ruoxi Li, ${ }^{1, \#}$ Dazheng Ling, ${ }^{1, \#}$ Tongke Tang, ${ }^{2,5, \#}$ Zhenghui Huang, ${ }^{2}$ Manjiong Wang, ${ }^{1}$ Yan Ding, ${ }^{6}$ Taiping Liu, ${ }^{6}$ Hanwen Wei, ${ }^{1}$ Wenyue $\mathrm{Xu},{ }^{6}$ Fei Mao, ${ }^{1}$ Jin Zhu, ${ }^{1}$ Xiaokang $\mathrm{Li}^{1,}{ }^{1,}$ Lubin Jiang, ${ }^{2,5, *} \mathrm{Jian} \mathrm{Li},{ }^{1,3,4, *}$

${ }^{1}$ State Key Laboratory of Bioreactor Engineering, Shanghai Key Laboratory of New Drug Design, School of Pharmacy, East China University of Science and Technology, Shanghai 200237, China

${ }^{2}$ Key Laboratory of Molecular Virology and Immunology, Institut Pasteur of Shanghai, University of Chinese Academy of Sciences, Chinese Academy of Sciences, Shanghai 200031, China

${ }^{3}$ College of Pharmacy and Chemistry, Dali University, 5 Xue Ren Road, Dali 671000, China

${ }^{4}$ Frontiers Science Center for Materiobiology and Dynamic Chemistry, East China University of Science and Technology, 130 Mei Long Road, Shanghai 200237, China ${ }^{5}$ School of Life Science and Technology, ShanghaiTech University, Shanghai 201210, P.R. China

${ }^{6}$ Department of Pathogenic Biology, Army Medical University, Chongqing 400038, China

\#These authors contributed equally to this work.

*Correspondence: Jian Li (jianli@ecust.edu.cn), Lubin Jiang (1bjiang@ips.ac.cn), Xiaokang Li (kli@ecust.edu.cn) 


\section{Table of Contents}

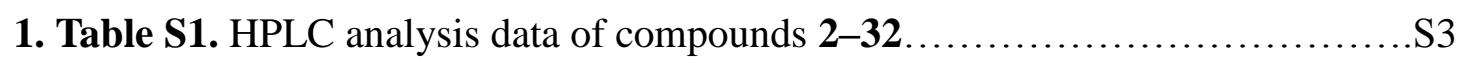

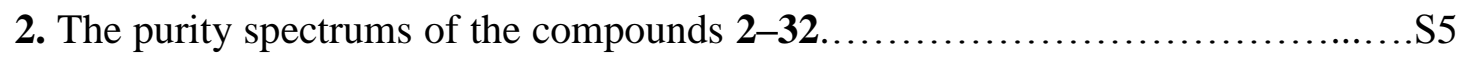

3. Figure S1. Body weight date of in vivo erythrocytic antimalarial assay..........S20

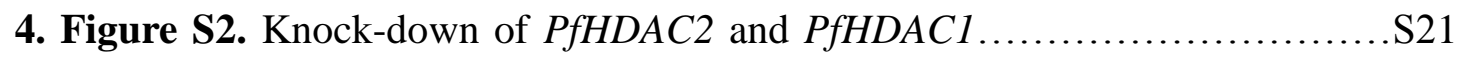

5. Figure. S3 Western Blot Identification of Knock-down of PfHDAC1 ...........S22

6. Figure S4. Repetitive Examination of Acetylation Level of P. falciparum Histone

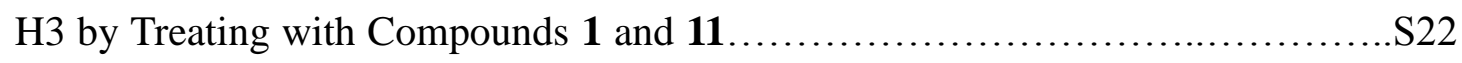

7. Table S2. Primers used in $P f H D A C 1 / 2$ gene knock-down study...............S23 
1. Table S1. HPLC analysis data of compounds 2-32. The HPLC purities of compounds 2-32 that were essential to the conclusions drawn in the text and determined by a standard instrumentation the following table. The peak purity was checked with UV spectra.

\begin{tabular}{|c|c|c|c|}
\hline & & \multicolumn{2}{|c|}{ Method } \\
\hline \multicolumn{2}{|c|}{ Equipment } & \multicolumn{2}{|c|}{$\begin{array}{l}\text { Agilent } 1100 \text { with quaternary pump, diode-array detector } \\
\text { (DAD) }\end{array}$} \\
\hline \multicolumn{2}{|c|}{ Column } & \multicolumn{2}{|c|}{ Agilent Exlipse Plus C18 $(250 \times 4.6 \mathrm{~mm}, 5 \mu \mathrm{m}$ particle size $)$} \\
\hline \multicolumn{2}{|c|}{ System condition } & \multicolumn{2}{|c|}{$\begin{array}{l}\text { Acetonitrile, flow rate: } 0.5 \mathrm{~mL} / \mathrm{min} \text {, calculated the relactive } \\
\text { purity of each compound at } 254 \mathrm{nM}\end{array}$} \\
\hline \multirow{11}{*}{ Results } & Compd & Retention time (min) & Relactive purity (\%) \\
\hline & 2 & 5.079 & 100 \\
\hline & 3 & 5.117 & 99.8 \\
\hline & 4 & 5.168 & 99.6 \\
\hline & 5 & 5.122 & 100 \\
\hline & 6 & 5.093 & 99.2 \\
\hline & 7 & 5.110 & 95 \\
\hline & 8 & 5.116 & 100 \\
\hline & 9 & 5.080 & 95.6 \\
\hline & 10 & 5.022 & 99.9 \\
\hline & 11 & 5.023 & 97.3 \\
\hline
\end{tabular}




\begin{tabular}{|c|c|c|}
\hline 12 & 5.087 & 98.9 \\
\hline 13 & 5.090 & 95.2 \\
\hline 14 & 5.112 & 98 \\
\hline 15 & 5.113 & 98.2 \\
\hline 16 & 5.052 & 100 \\
\hline 17 & 5.082 & 99.9 \\
\hline 18 & 5.057 & 100 \\
\hline 19 & 5.060 & 100 \\
\hline 20 & 5.107 & 99.4 \\
\hline 21 & 5.124 & 99.9 \\
\hline 22 & 5.102 & 100 \\
\hline 23 & 5.121 & 98.9 \\
\hline 24 & 5.114 & 100 \\
\hline 25 & 5.100 & 100 \\
\hline 26 & 5.110 & 100 \\
\hline 27 & 5.100 & 100 \\
\hline 28 & 5.098 & 99 \\
\hline 29 & 5.090 & 100 \\
\hline 30 & 5.082 & 100 \\
\hline 31 & 5.140 & 95.4 \\
\hline 32 & 5.120 & 99.2 \\
\hline
\end{tabular}


2. The purity spectrums of the compounds $\mathbf{2}-\mathbf{3 2}$.

\section{Compound 2}

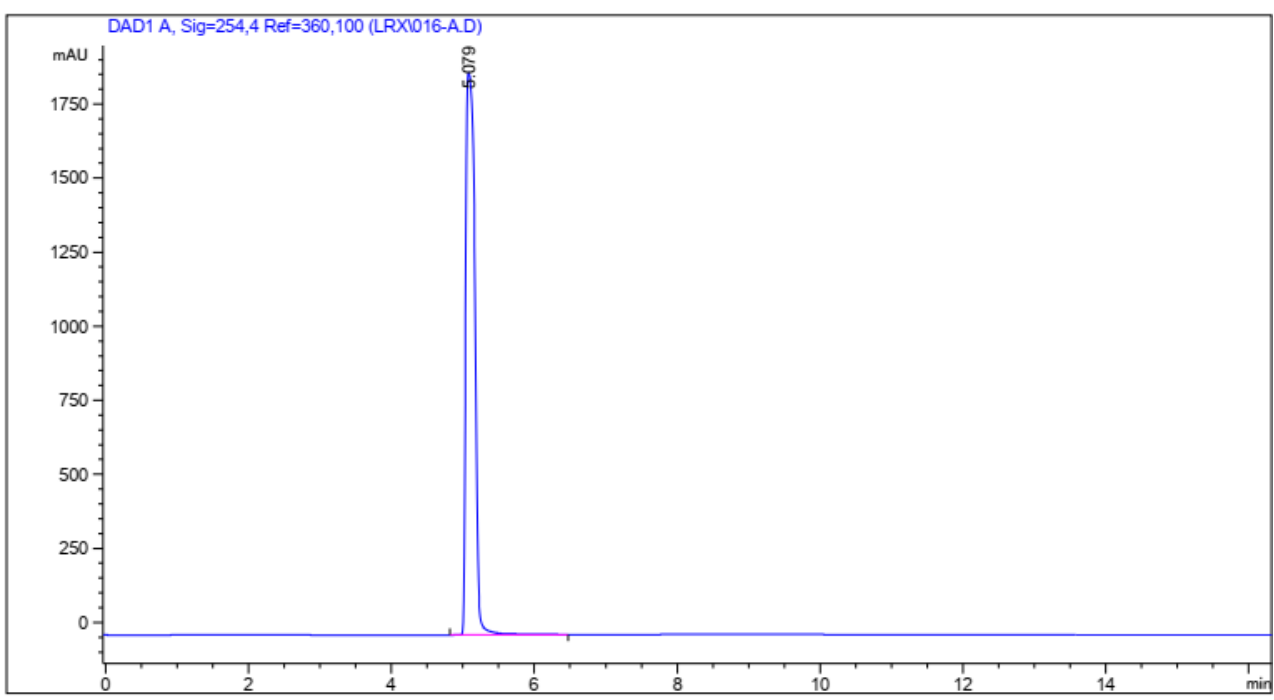

信号 1: DAD1 A, Sig=254,4 Ref $=360,100$

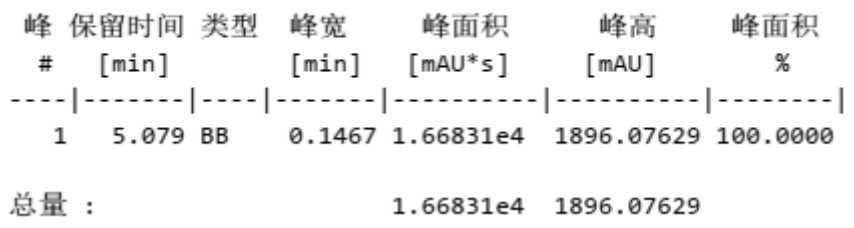

\section{Compound $\mathbf{3}$}

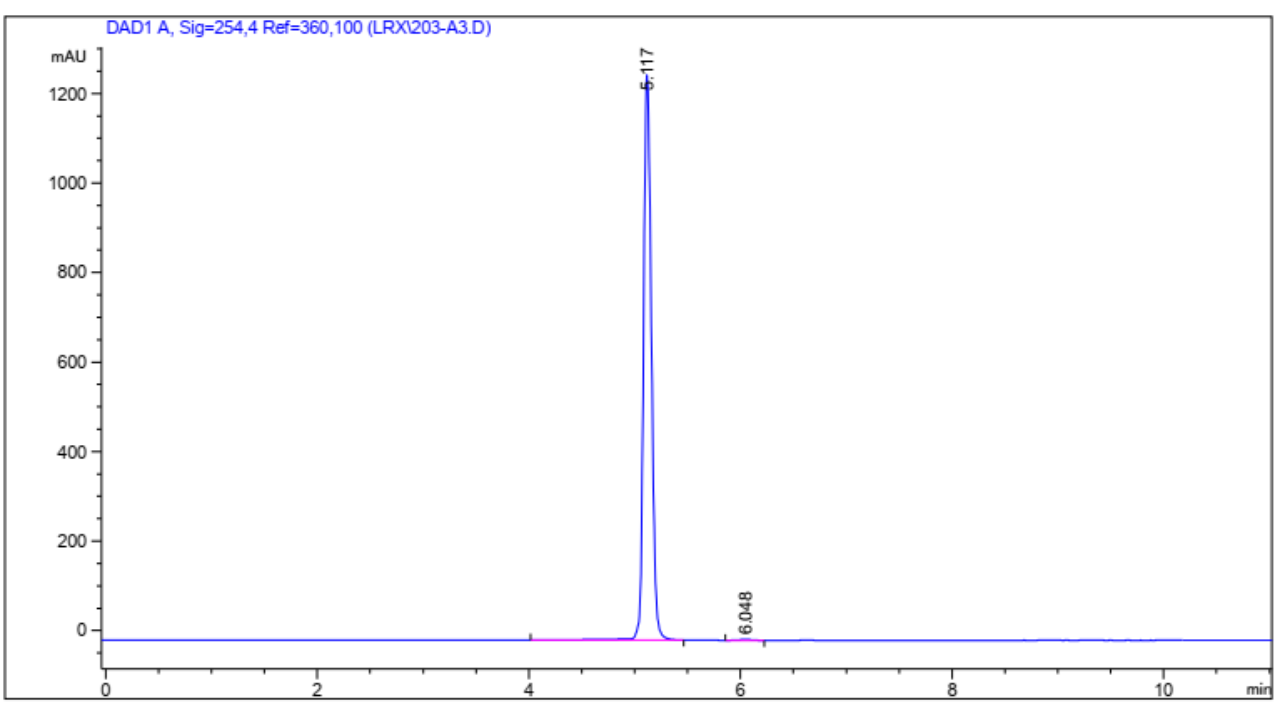

信号 1: DAD1 A, Sig $=254,4$ Ref $=360,100$

\begin{tabular}{|c|c|c|c|c|c|c|}
\hline 峰 & $\begin{array}{c}\text { 保留时间 } \\
\text { [min] }\end{array}$ & 类型 & $\begin{array}{l}\text { 峰宽 } \\
\text { [min] }\end{array}$ & $\begin{array}{r}\text { 峰面积 } \\
{\left[\mathrm{mAU}^{*} \mathrm{~s}\right]}\end{array}$ & $\begin{array}{r}\text { 峰高 } \\
\text { [mAU] }\end{array}$ & $\begin{array}{c}\text { 峰面积 } \\
\%\end{array}$ \\
\hline & 5.117 & BB & 0.0829 & 6590.69824 & 1262.98254 & 99.7664 \\
\hline 2 & 6.048 & & 0.1163 & 15.43255 & 1.99317 & 0.2336 \\
\hline
\end{tabular}




\section{Compound 4}

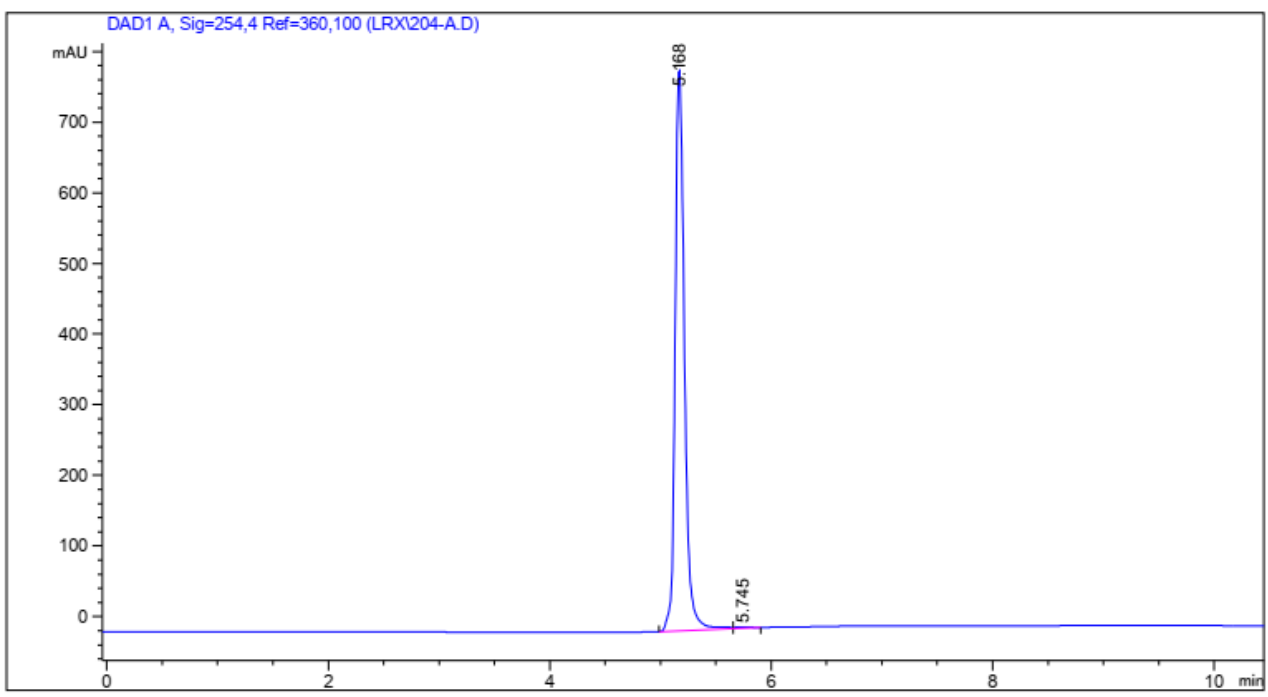

信号 1: DAD1 A, Sig $=254,4$ Ref $=360,100$

\begin{tabular}{|c|c|c|c|c|c|c|}
\hline 峰 & $\begin{array}{c}\text { 保留时间 } \\
\text { [min] }\end{array}$ & 类型 & $\begin{array}{l}\text { 峰宽 } \\
\text { [min] }\end{array}$ & $\begin{array}{r}\text { 峰面积 } \\
\text { [mAU*s ] }\end{array}$ & $\begin{array}{r}\text { 峰高 } \\
\text { [mAU] }\end{array}$ & $\begin{array}{c}\text { 峰面积 } \\
\%\end{array}$ \\
\hline & |-.... & & - . & 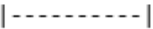 & | & | \\
\hline 1 & 5.168 & BV & 0.0902 & 4644.22217 & 794.43994 & 99.5920 \\
\hline 2 & 5.745 & VB & 0.1384 & 19.02420 & 1.97444 & 0.4080 \\
\hline 总量 & & & & 4663.24637 & 796.41439 & \\
\hline
\end{tabular}

\section{Compound 5}

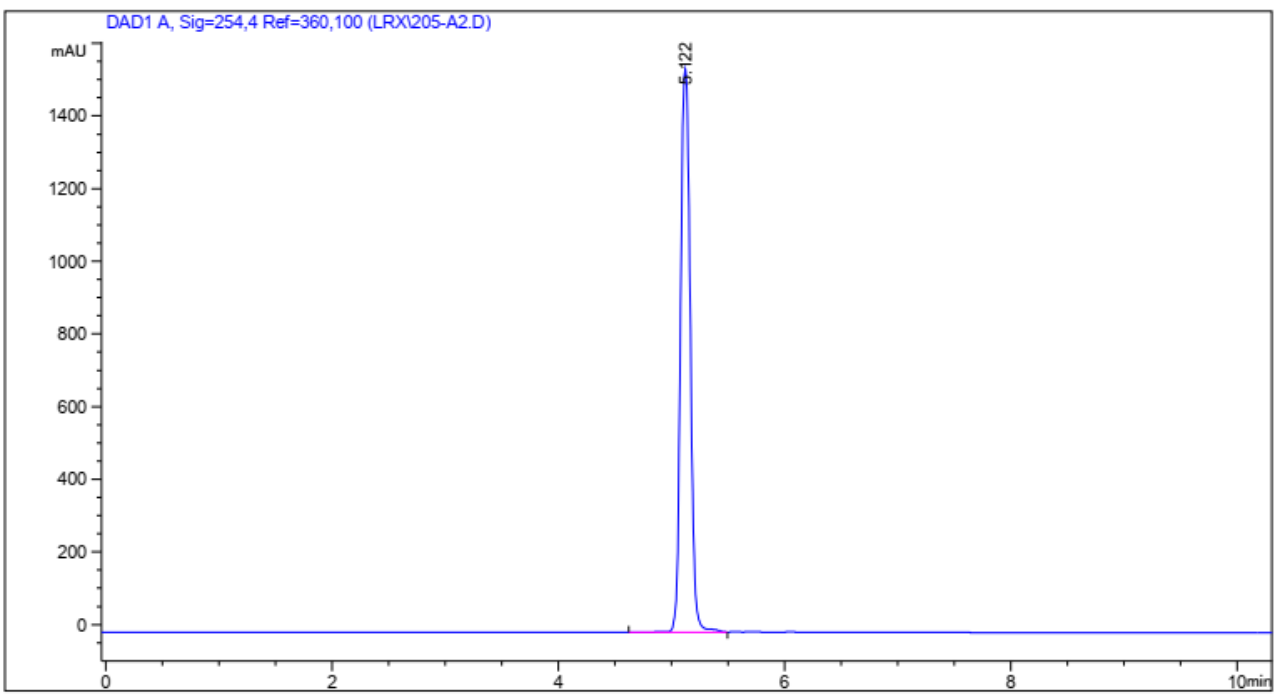

信号 1: DAD1 A, Sig=254,4 Ref $=360,100$

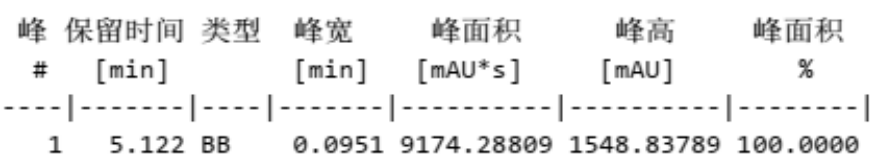

总量 :

9174.288091548 .83789 


\section{Compound 6}

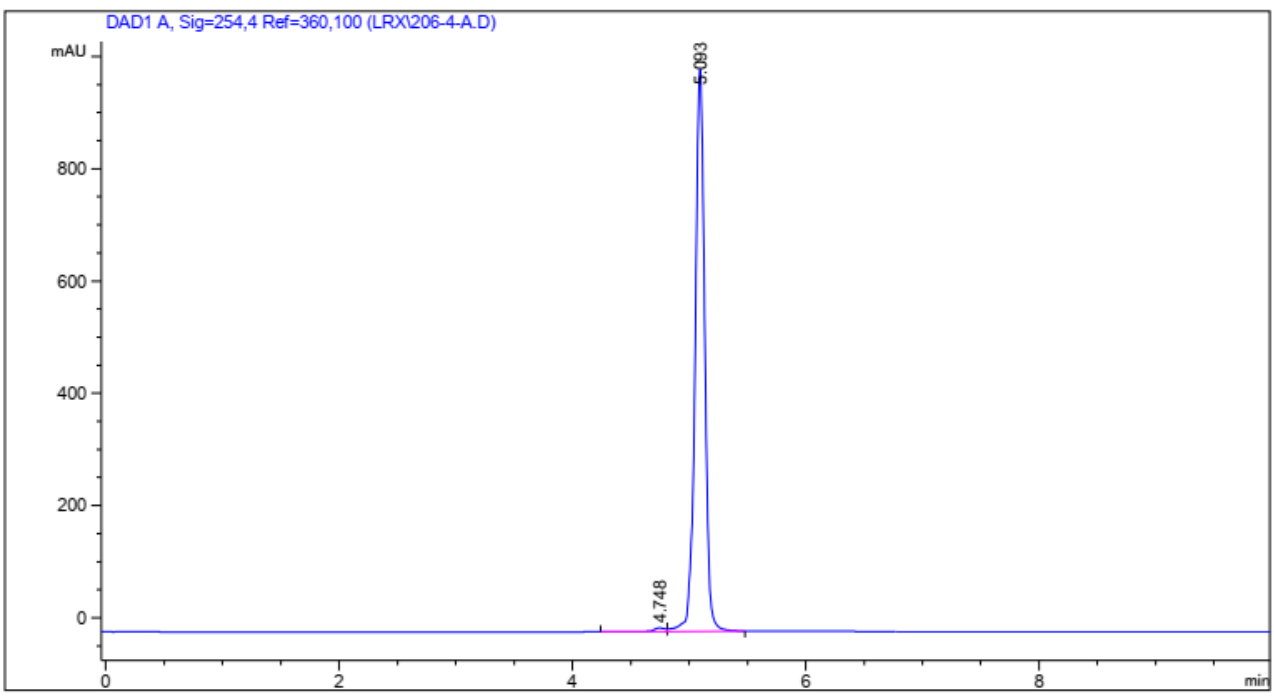

信号 1: DAD1 A, Sig $=254,4$ Ref $=360,100$

\begin{tabular}{|c|c|c|c|c|c|c|}
\hline 峰 & $\begin{array}{c}\text { 保留时间 } \\
\text { [min] }\end{array}$ & 类型 & $\begin{array}{l}\text { 峰宽 } \\
\text { [min] }\end{array}$ & $\begin{array}{c}\text { 峰面积 } \\
\text { [mAU*s] }\end{array}$ & $\begin{array}{r}\text { 峰高 } \\
\text { [mAU] }\end{array}$ & $\begin{array}{c}\text { 峰面积 } \\
\text { \% }\end{array}$ \\
\hline & & & & & & \\
\hline & & & & $\begin{array}{r}44.76023 \\
5765.16162\end{array}$ & 0.28700 & 0.1095 \\
\hline
\end{tabular}

总量 :

5809.867851007 .14613

\section{Compound 7}

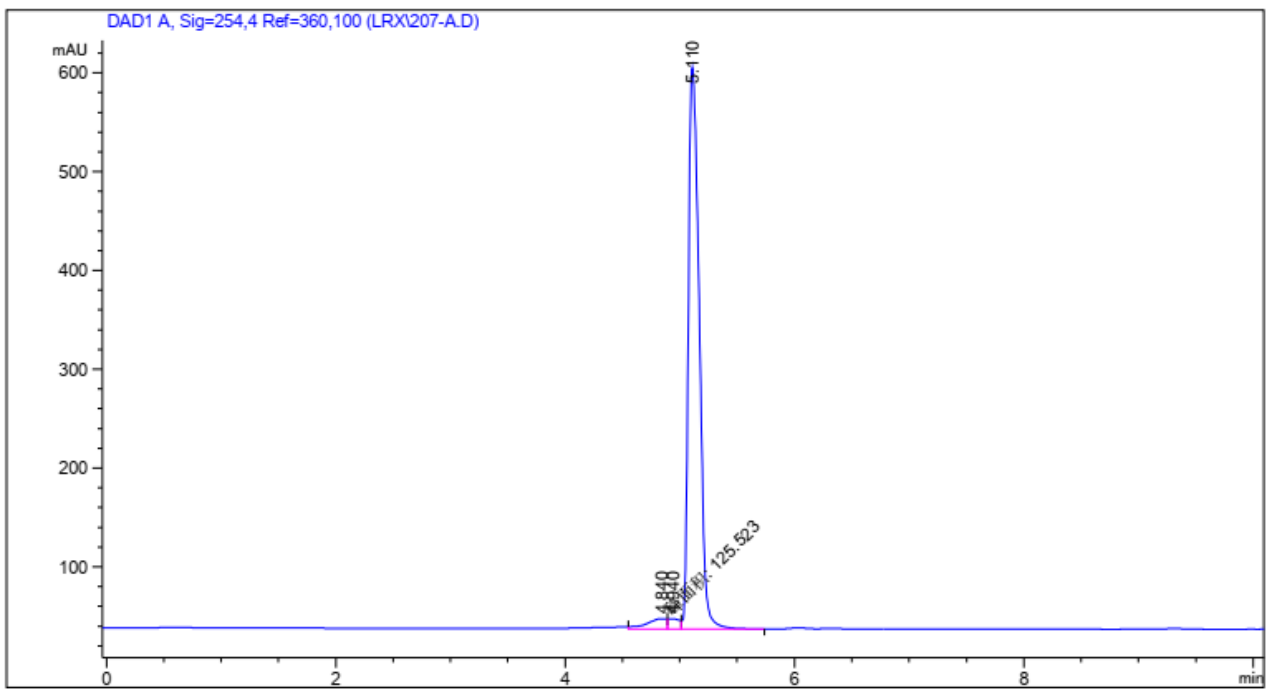

信号 1: DAD1 A, Sig $=254,4$ Ref $=360,100$

$$
\begin{aligned}
& \text { 峰 保留时间类型 峰宽 峰面积 峰高 峰面积 } \\
& \begin{array}{lllll}
\# & {[\mathrm{~min}]} & {[\mathrm{min}]} & {[\mathrm{mAU} * \mathrm{~s}]} & {[\mathrm{mAU}]}
\end{array} \\
& \begin{array}{l}
-1 \\
1
\end{array} 4.840 \text { FM } 0.2047 \quad 125.52267 \quad 10.21945 \quad 3.2127 \\
& \begin{array}{llllll}
1 & 4.840 \mathrm{FM} & 0.2047 & 125.52267 & 10.21945 & 3.2127
\end{array} \\
& \begin{array}{rrrrrr}
2 & 4.940 \mathrm{VV} & 0.1016 & 69.29819 & 10.15378 & 1.7737 \\
3 & 5.110 \mathrm{VB} & 0.1083 & 3712.20581 & 567.72357 & 95.0136
\end{array} \\
& \text { 总量： } \quad 3907.02667 \quad 588.09680
\end{aligned}
$$




\section{Compound 8}

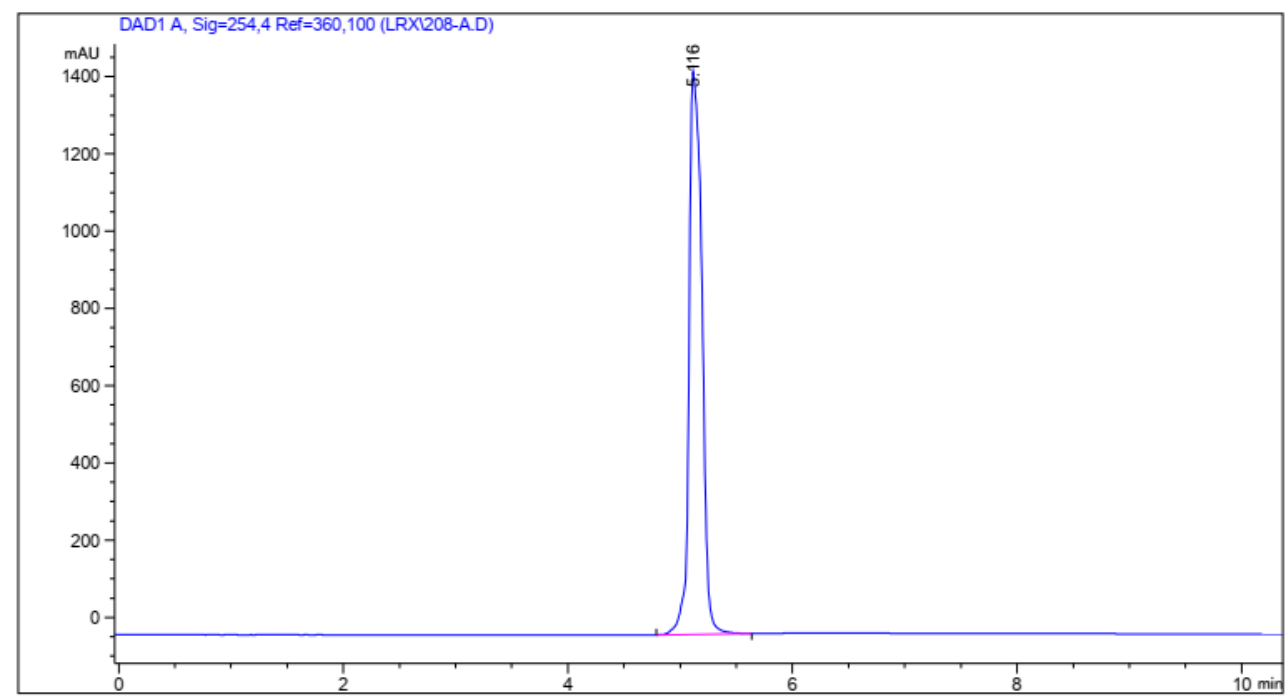

信号 1: DAD1 A, Sig=254,4 Ref $=360,100$

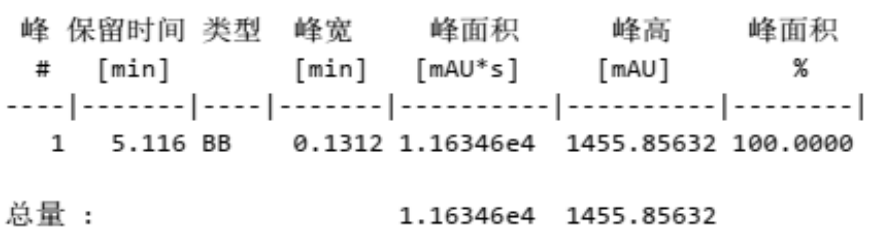

\section{Compoumd 9}

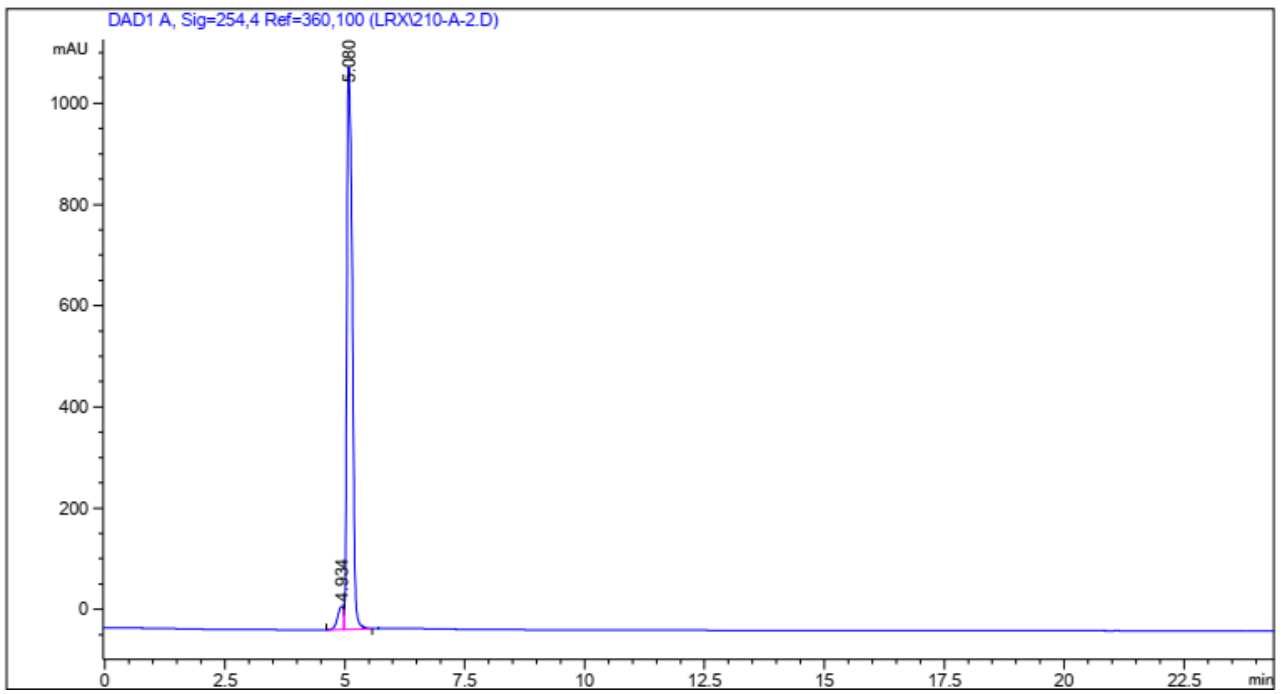

信号 1: DAD1 A, Sig=254,4 Ref $=360,100$

\begin{tabular}{cccccc}
$\begin{array}{c}\text { 峰 保留时间 类型 } \\
\text { [min] }\end{array}$ & $\begin{array}{c}\text { 峰宽 } \\
\text { [min] }\end{array}$ & $\begin{array}{c}\text { 峰面积 } \\
{[\text { mAU*s] }}\end{array}$ & $\begin{array}{c}\text { 峰高 } \\
\text { [mAU] }\end{array}$ & $\begin{array}{c}\text { 峰面积 } \\
\%\end{array}$ \\
\hline 1 & 4.934 BV & 0.1384 & 402.16003 & 45.82555 & 4.3528 \\
\hline 2 & $5.080 \mathrm{VV}$ & 0.1326 & 8837.04004 & 1113.00110 & 95.6472
\end{tabular}

总量 :

9239.200071158 .82664 


\section{Compound 10}

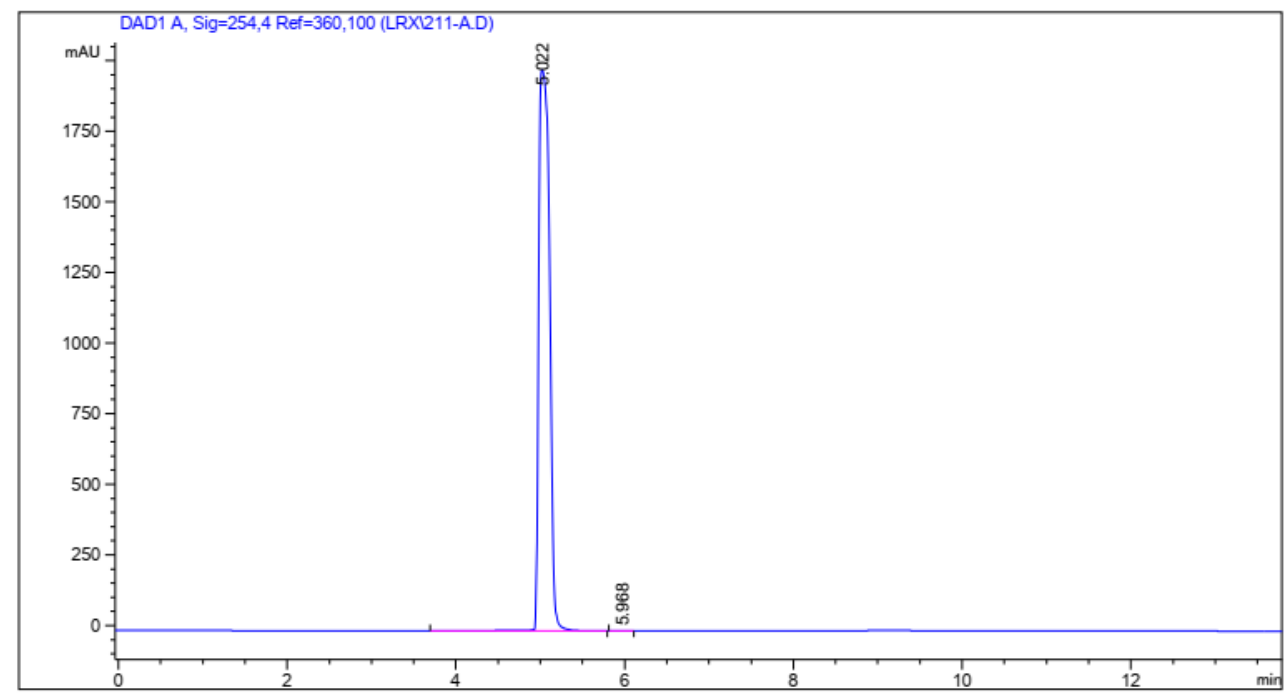

信号 1: DAD1 A, Sig $=254,4$ Ref $=360,100$

\begin{tabular}{|c|c|c|c|c|c|c|}
\hline $\begin{array}{r}\text { 峰 } \\
\#\end{array}$ & $\begin{array}{c}\text { 保留时间 } \\
\text { [min] }\end{array}$ & 类型 & $\begin{array}{l}\text { 峰宽 } \\
\text { [min] }\end{array}$ & $\begin{array}{r}\text { 峰面积 } \\
\text { [mAU*s] }\end{array}$ & $\begin{array}{r}\text { 峰高 } \\
\text { [mAU] }\end{array}$ & $\begin{array}{c}\text { 峰面积 } \\
\text { \% }\end{array}$ \\
\hline & & & & & & \\
\hline 1 & 5.022 & BB & 0.1487 & $1.78261 \mathrm{e} 4$ & 1985.87085 & 99.9479 \\
\hline 2 & 5.968 & BB & 0.1530 & 9.29229 & 1.01279 & 0.0521 \\
\hline 总量 r & & & & $1.78354 \mathrm{e} 4$ & 1986.88364 & \\
\hline
\end{tabular}

\section{Compound 11}

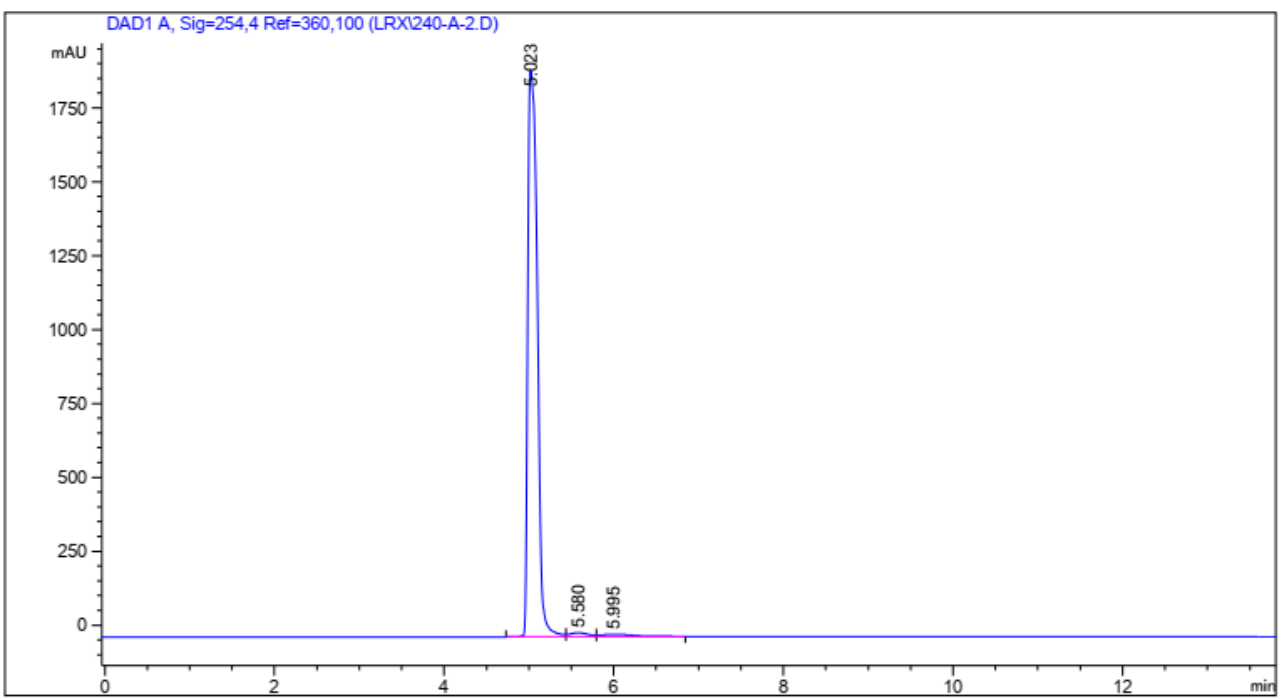

信号 1: DAD1 A, Sig=254,4 Ref $=360,100$

\begin{tabular}{|c|c|c|c|c|c|c|}
\hline 峰 & $\begin{array}{c}\text { 保留时间 } \\
\text { [min] }\end{array}$ & 类型 & $\begin{array}{l}\text { 峰宽 } \\
\text { [min] }\end{array}$ & $\begin{array}{r}\text { 峰面积 } \\
\text { [mAU*s ] }\end{array}$ & $\begin{array}{r}\text { 峰高 } \\
\text { [mAU] }\end{array}$ & $\begin{array}{c}\text { 峰面积 } \\
\text { \% }\end{array}$ \\
\hline & & & & & & 07,2799 \\
\hline 1 & 5.023 & BV & 0.1292 & $1.49568 \mathrm{e} 4$ & 1914.24622 & 97.2700 \\
\hline 2 & 5.580 & vv & 0.2202 & 206.77313 & 13.84866 & 1.3447 \\
\hline 3 & 5.995 & VB & 0.4199 & 213.00633 & 7.86723 & 1.3853 \\
\hline & & & & $1.53766 \mathrm{e} 4$ & 1935.96210 & \\
\hline
\end{tabular}




\section{Compound 12}

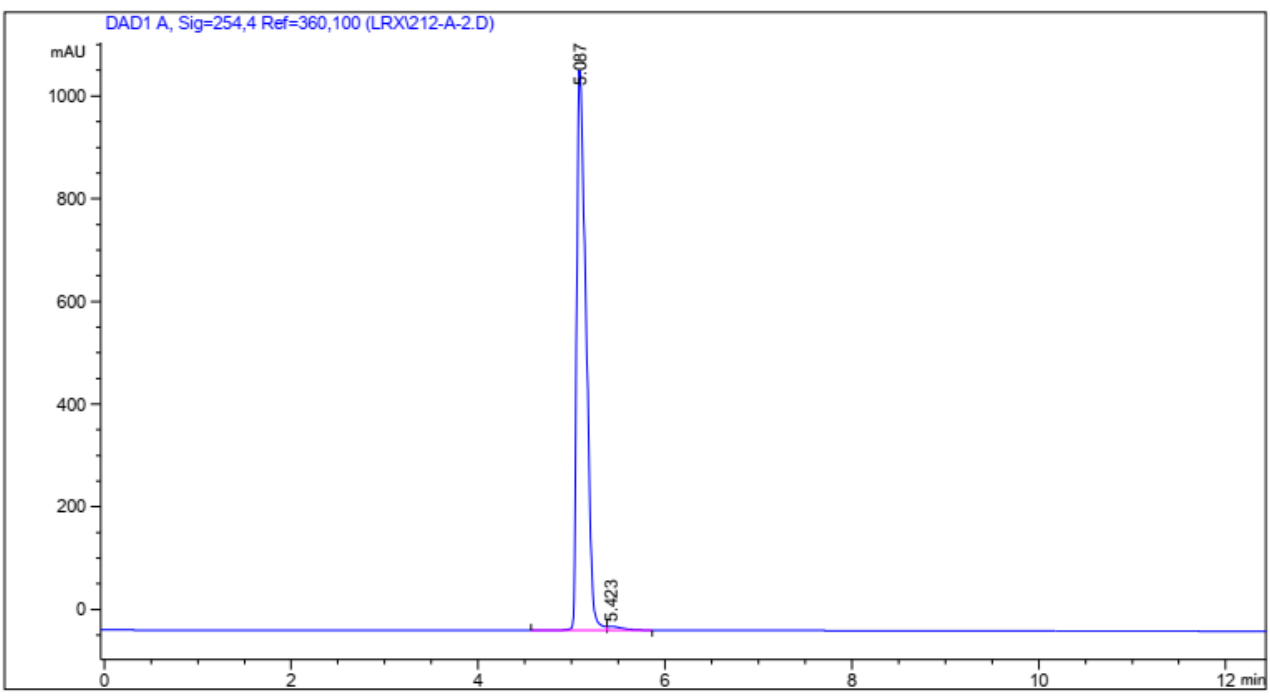

信号 1: DAD1 A, Sig=254,4 Ref $=360,100$

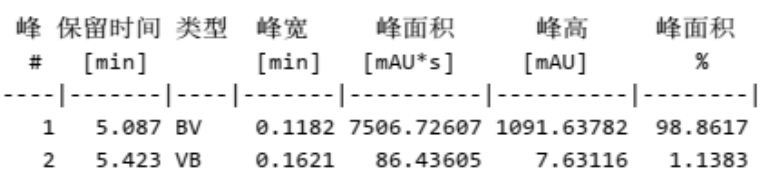

总量 :

$7593.16212 \quad 1099.26898$

\section{Compound 13}

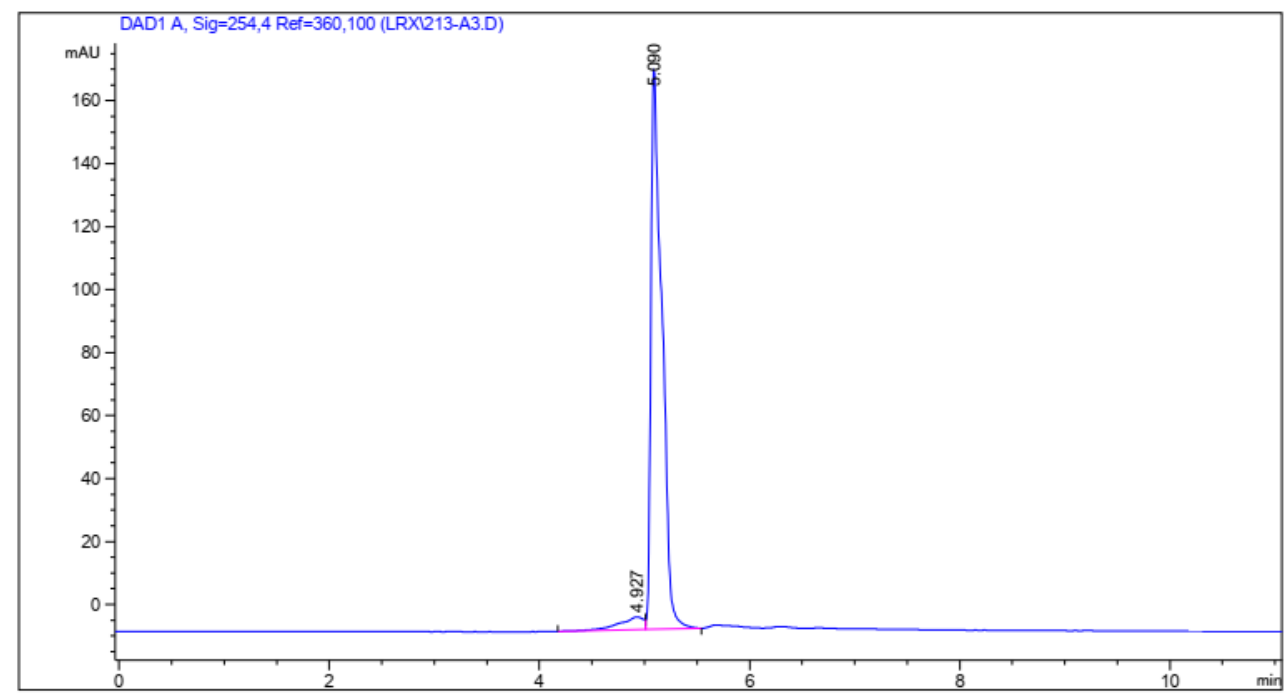

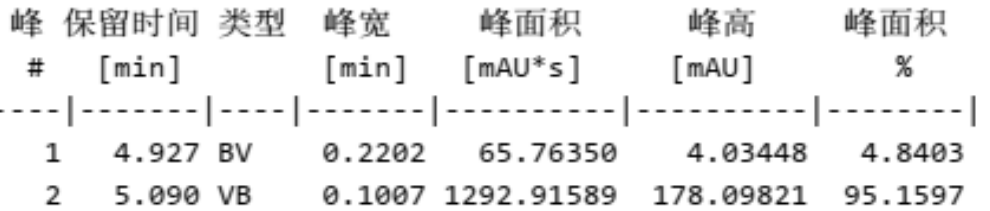

总量：

1358.67940

182.13268 


\section{Compound 14}

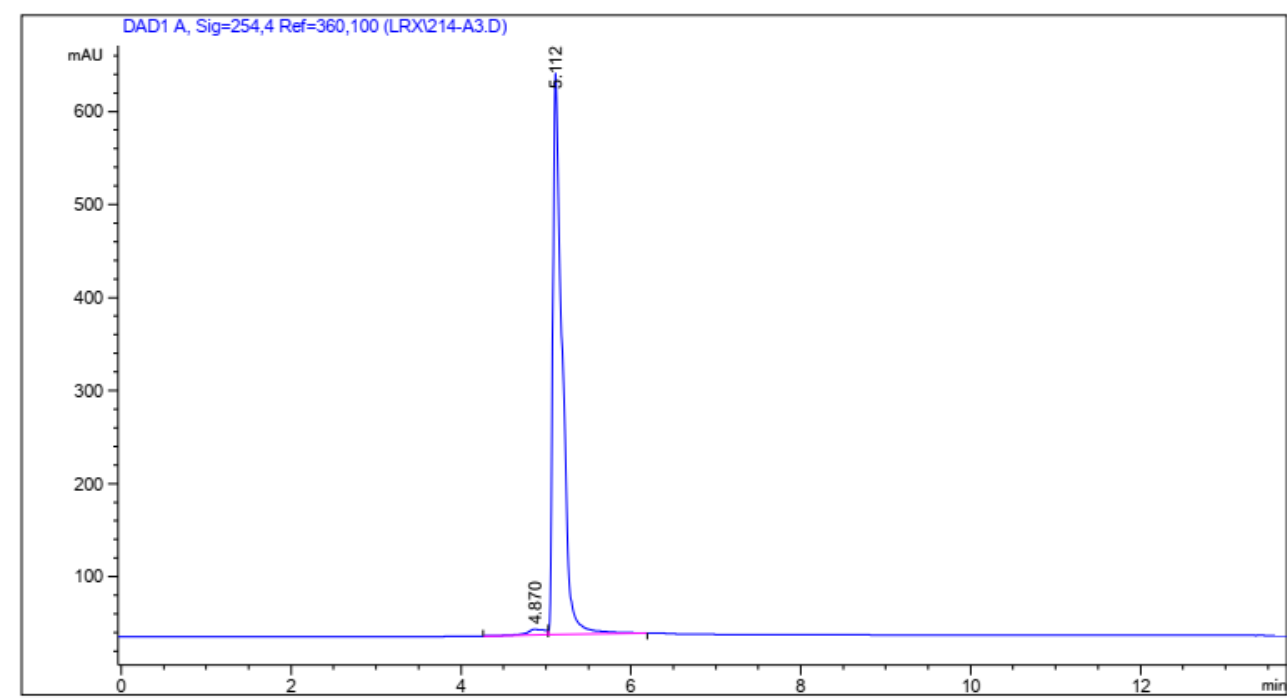

\begin{tabular}{|c|c|c|c|c|c|c|}
\hline $\begin{array}{c}\text { 峰 } 1 \\
\#\end{array}$ & $\begin{array}{c}\text { 保留时间 } \\
\text { [min] }\end{array}$ & 类型 & $\begin{array}{l}\text { 峰宽 } \\
\text { [min] }\end{array}$ & $\begin{array}{r}\text { 峰面积 } \\
\text { [mAU*s] }\end{array}$ & $\begin{array}{r}\text { 峰高 } \\
\text { [mAU] }\end{array}$ & $\begin{array}{c}\text { 峰面积 } \\
\text { \% }\end{array}$ \\
\hline & & & & $\mid \cdots-\cdots$ & - & $\mid \cdots-\cdots$ \\
\hline 1 & 4.870 & BV & 0.2049 & 93.49222 & 6.16521 & 1.9893 \\
\hline 2 & 5.112 & VB & 0.1051 & 4606.27881 & 603.30670 & 98.0107 \\
\hline 4 & & & & 4699.77103 & 609.47191 & \\
\hline
\end{tabular}

\section{Compound 15}

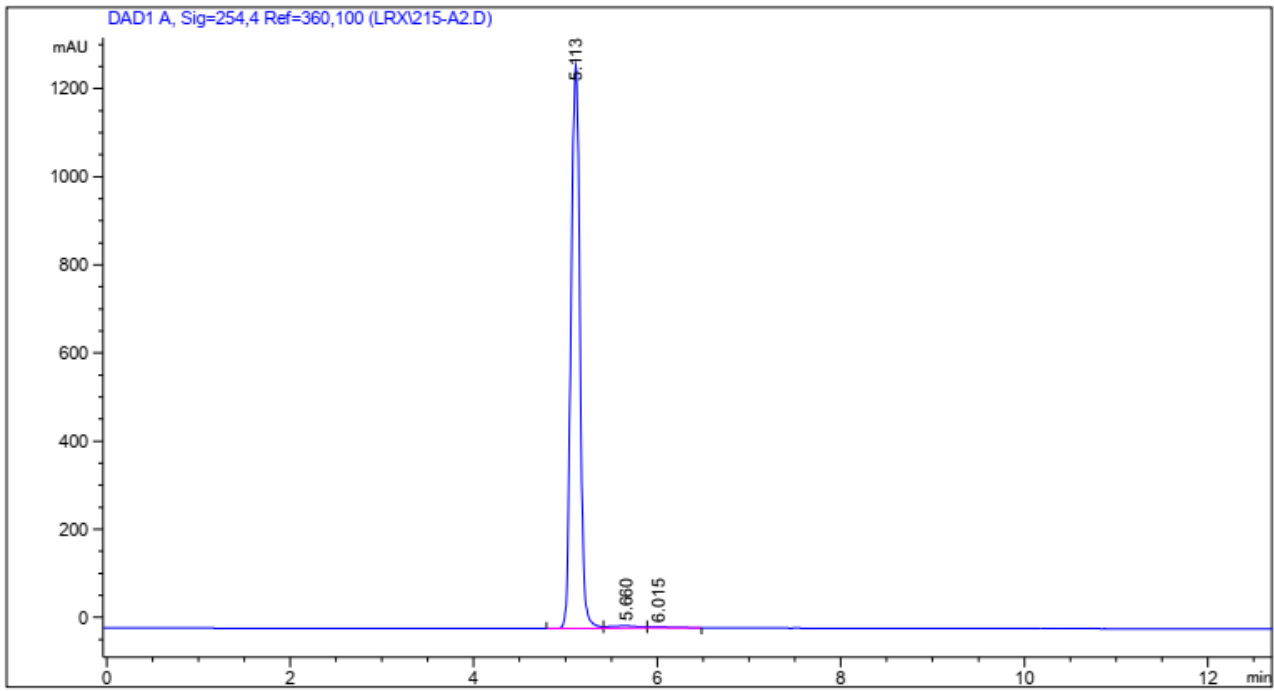

信号 1: DAD1 A, Sig $=254,4$ Ref $=360,100$

\begin{tabular}{|c|c|c|c|c|c|c|}
\hline $\begin{array}{r}\text { 峰 } \\
\text { \# }\end{array}$ & $\begin{array}{c}\text { 保留时间 } \\
\text { [min] }\end{array}$ & 类型 & $\begin{array}{l}\text { 峰宽 } \\
\text { [min] }\end{array}$ & $\begin{array}{r}\text { 峰面积 } \\
\text { [mAU*s] }\end{array}$ & $\begin{array}{r}\text { 峰高 } \\
\text { [mAU] }\end{array}$ & $\begin{array}{c}\text { 峰面积 } \\
\text { \% }\end{array}$ \\
\hline & & & & & & \\
\hline 1 & 5.113 & BV & 0.1084 & 8576.78027 & 1276.56567 & 98.1752 \\
\hline 2 & 5.660 & vv & 0.2946 & 110.64340 & 4.91644 & 1.2665 \\
\hline 3 & 6.015 & VB & 0.2167 & 48.77546 & 3.04862 & 0.5583 \\
\hline
\end{tabular}




\section{Compound 16}

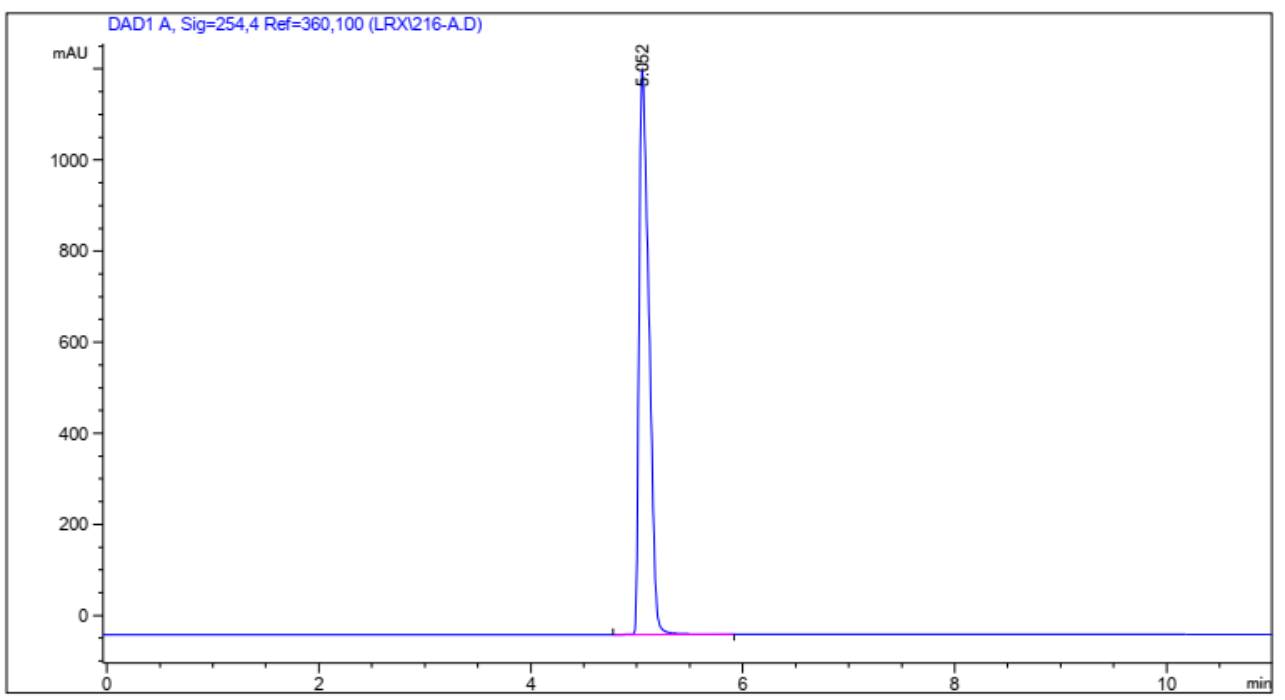

信号 1: DAD1 A, Sig=254,4 Ref $=360,100$

峰 保留时间 类型 峰宽 峰面积峰高峰面积

\# [min $] \quad[\mathrm{min}] \quad[\mathrm{mAU} * \mathrm{~s}] \quad[\mathrm{mAU}] \quad \%$

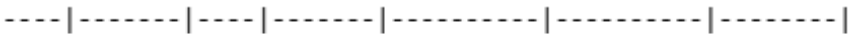

$1 \quad 5.052$ вв $0.1107 \quad 7936.41748 \quad 1238.77441 \quad 100.0000$

总量 :

$7936.41748 \quad 1238.77441$

\section{Compound 17}

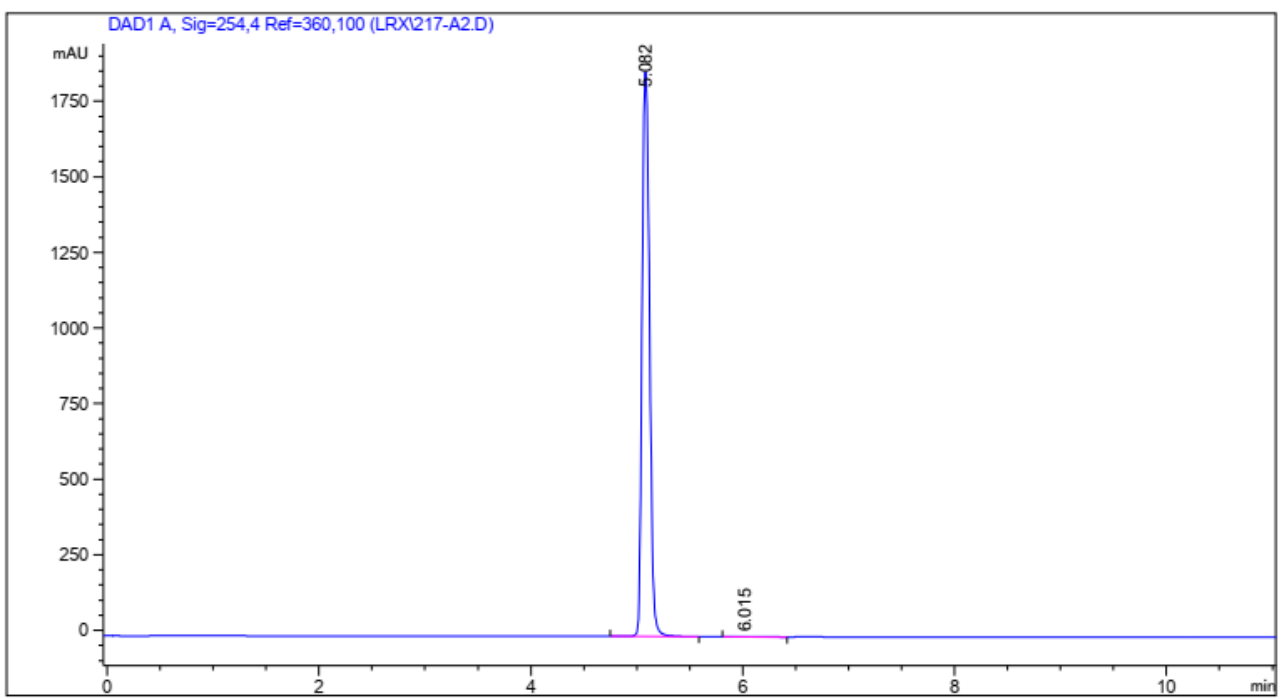

信号 1: DAD1 A, Sig $=254,4$ Ref $=360,100$

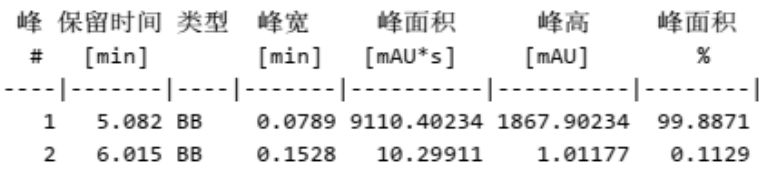

总量 :

9120.701451868 .91412 


\section{Compound 18}

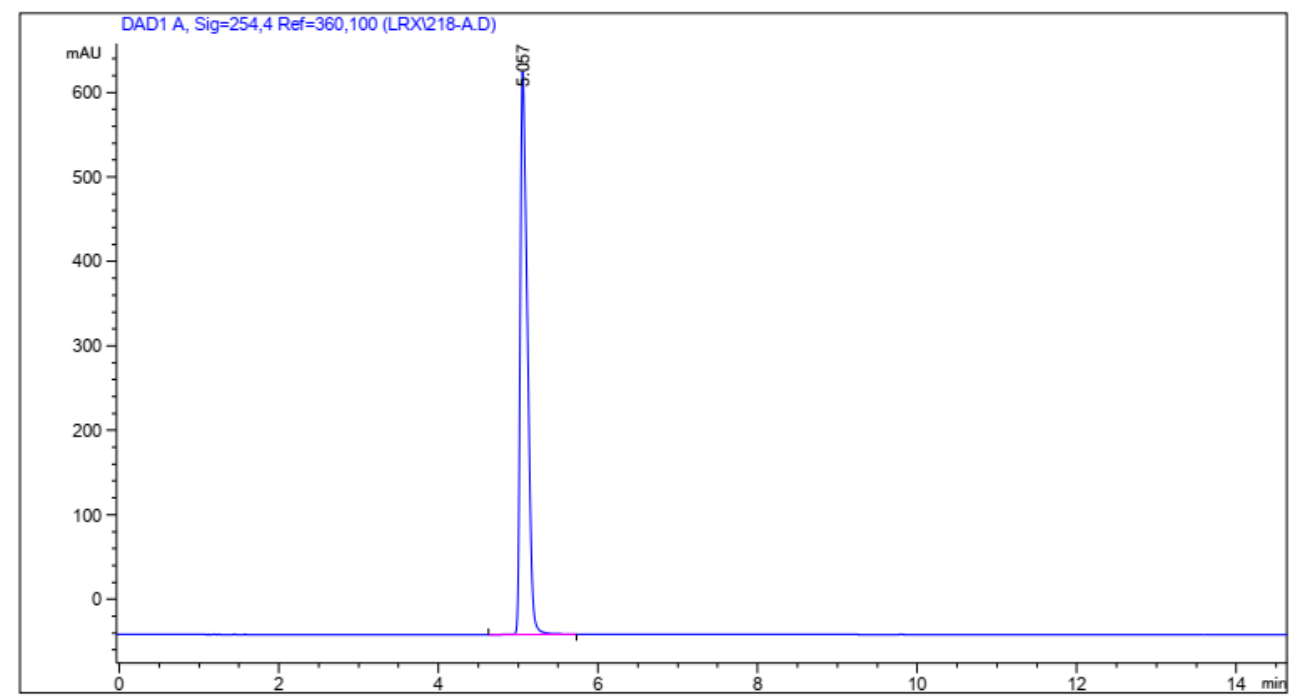

信号 1: DAD1 A, Sig=254,4 Ref $=360,100$

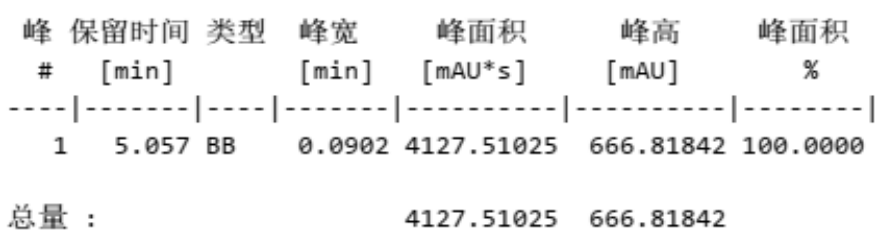

\section{Compound 19}

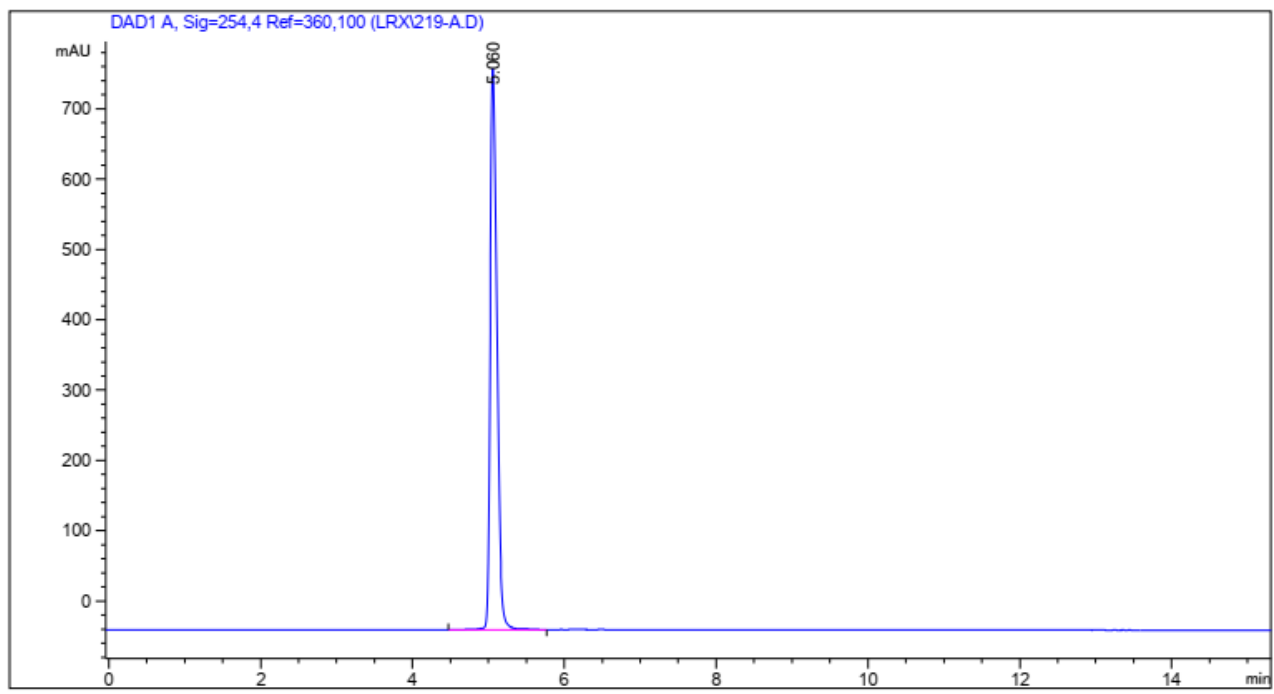

信号 1: DAD1 A, Sig $=254,4$ Ref $=360,100$

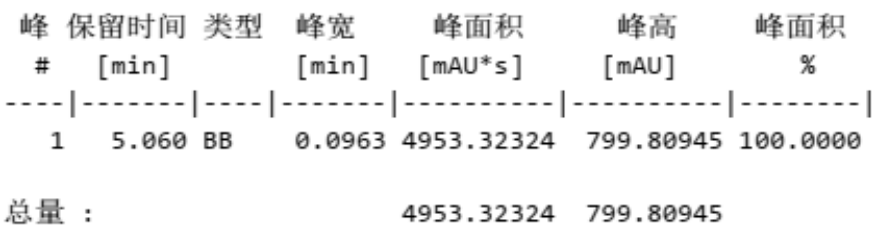




\section{Compound 20}

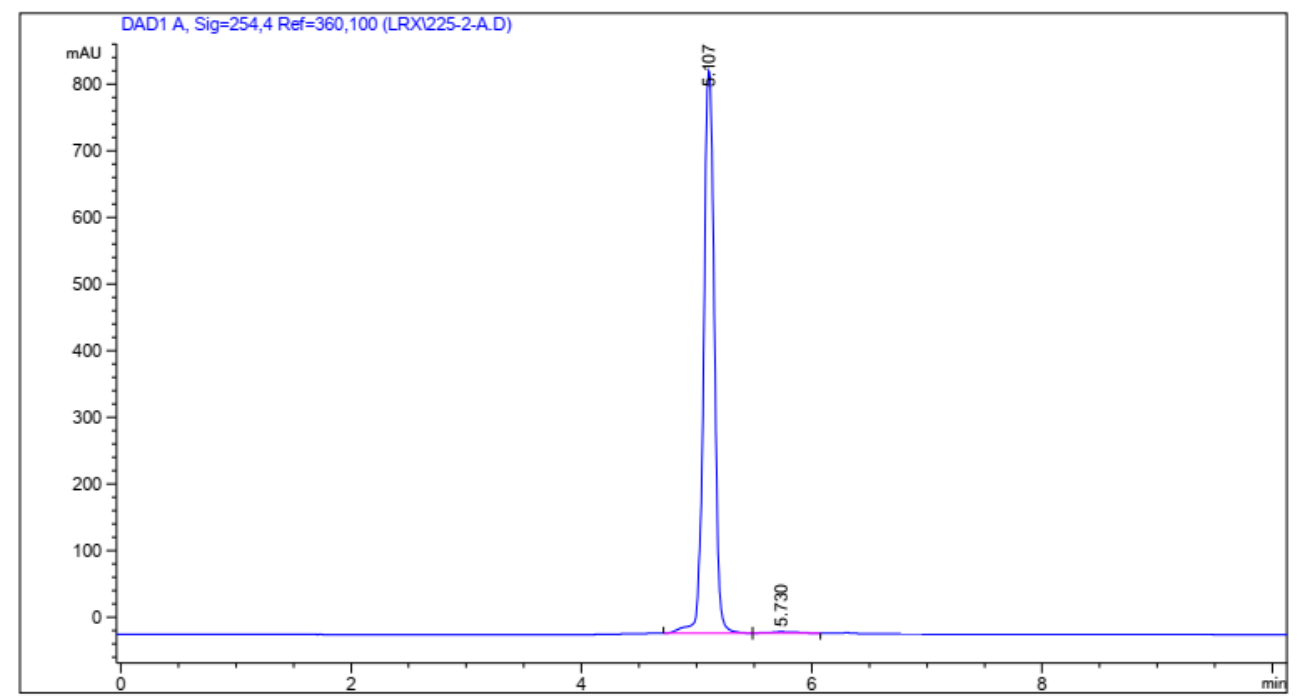

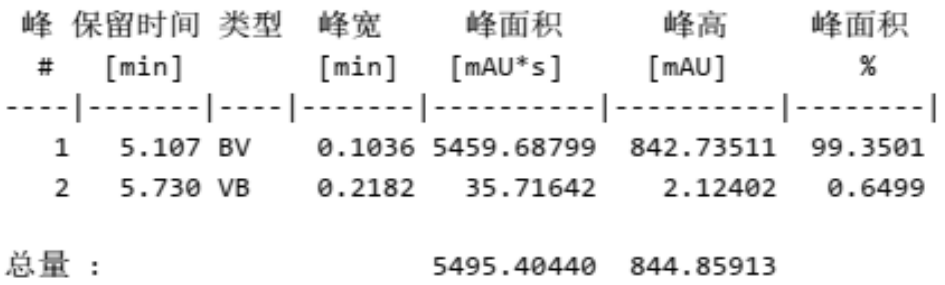

\section{Compound 21}

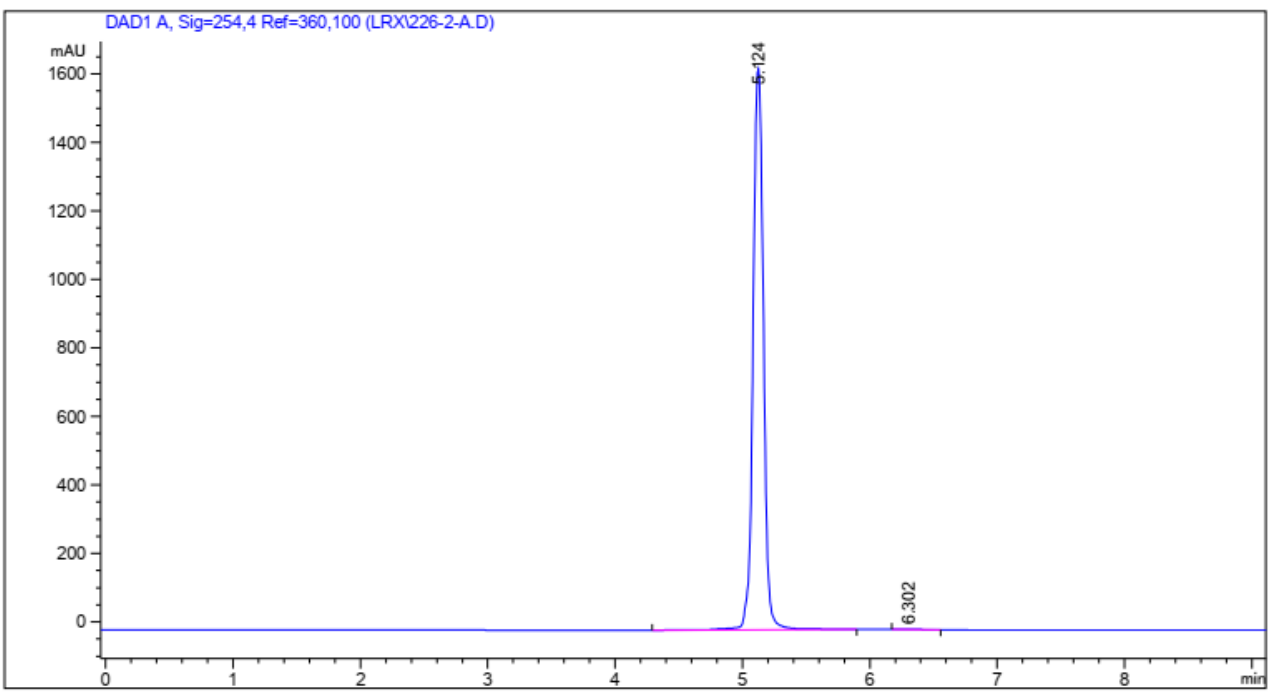

信号 1: DAD1 A, Sig $=254,4$ Ref $=360,100$

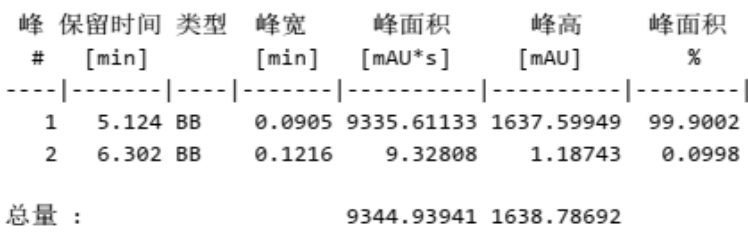




\section{Compound 22}

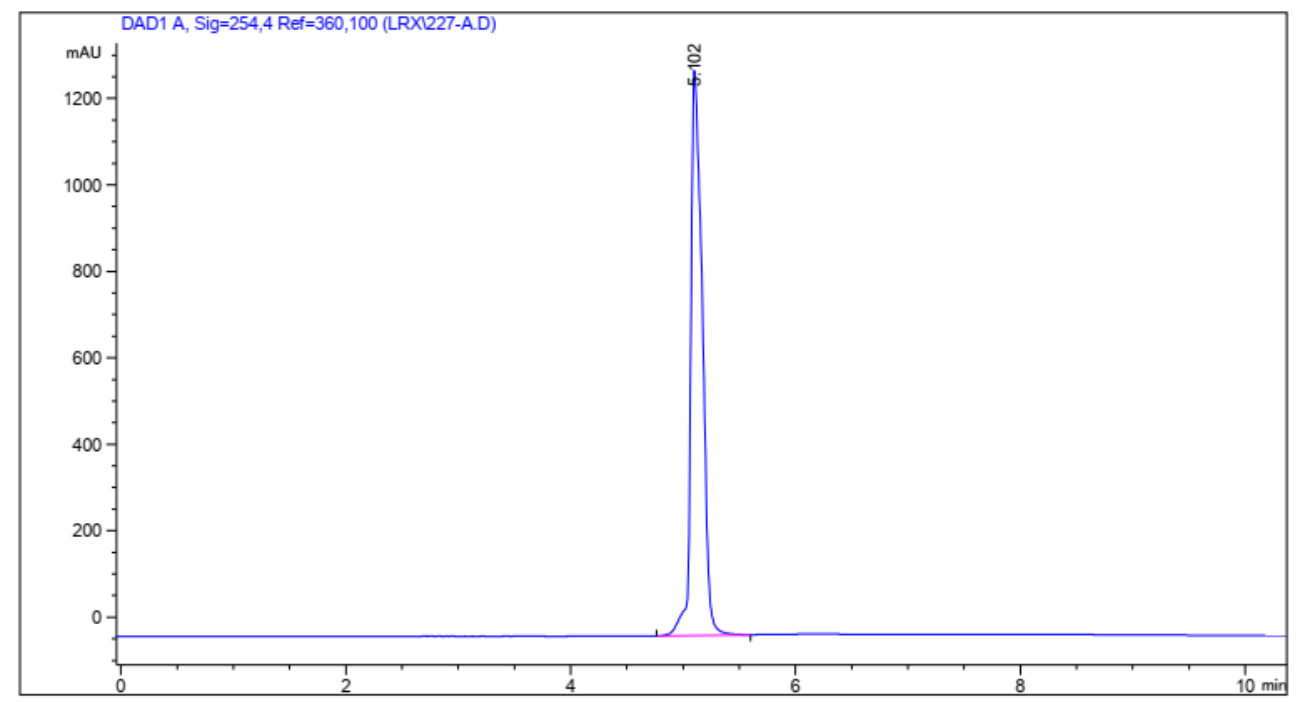

信号 1: DAD1 A, Sig=254,4 Ref $=360,100$

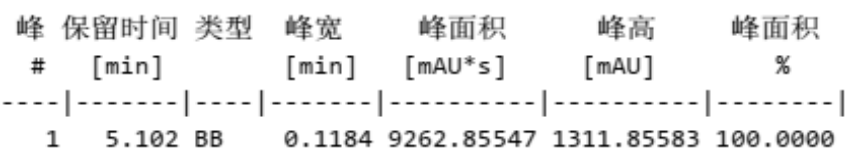

总量 :

9262.855471311 .85583

\section{Compound 23}

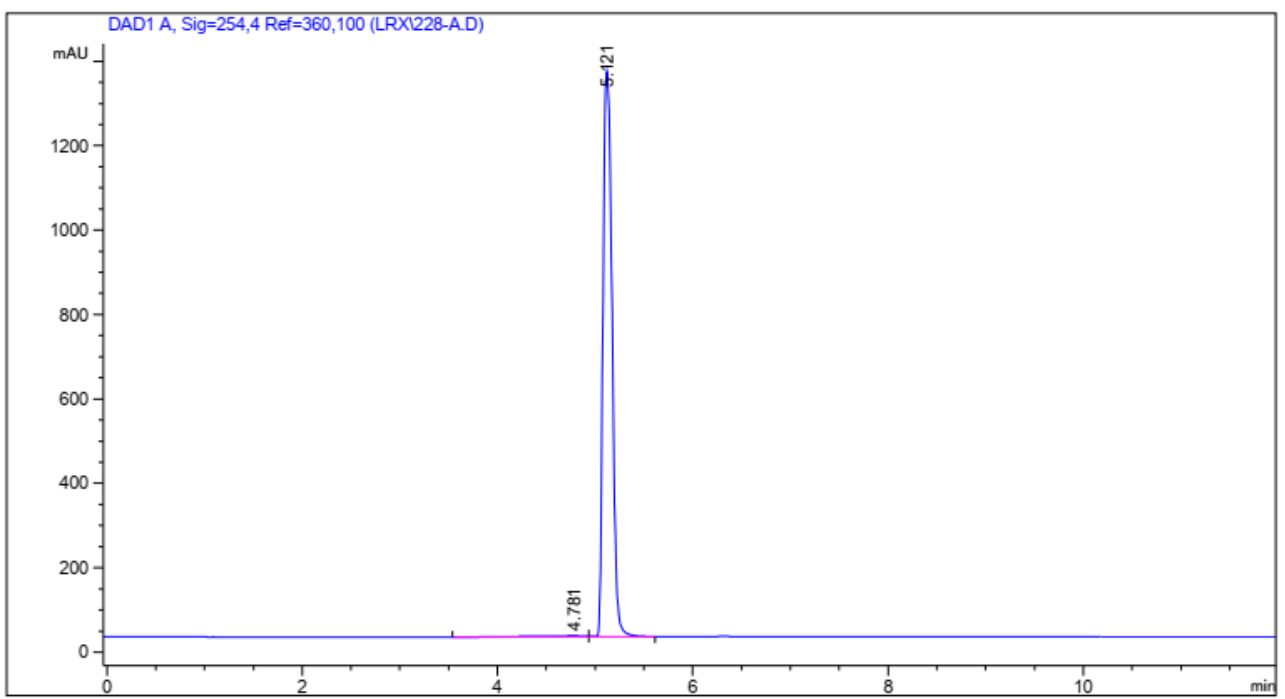

信号 1: DAD1 A, Sig $=254,4$ Ref $=360,100$

\begin{tabular}{|c|c|c|c|c|c|c|}
\hline 峰 & $\begin{array}{c}\text { 保留时间 } \\
\text { [min] }\end{array}$ & 类型 & $\begin{array}{l}\text { 峰宽 } \\
\text { [min] }\end{array}$ & $\begin{array}{r}\text { 峰面积 } \\
\text { [mAU*s] }\end{array}$ & $\begin{array}{r}\text { 峰高 } \\
\text { [mAU] }\end{array}$ & $\begin{array}{c}\text { 峰面积 } \\
\text { \% }\end{array}$ \\
\hline & & & & & & \\
\hline & 121 & & & 8693.17969 & $\begin{array}{r}2.31939 \\
1338.32727\end{array}$ & $\begin{array}{r}1.0830 \\
98.9170\end{array}$ \\
\hline
\end{tabular}

总量 :

8697.373641340 .64686 


\section{Compound 24}

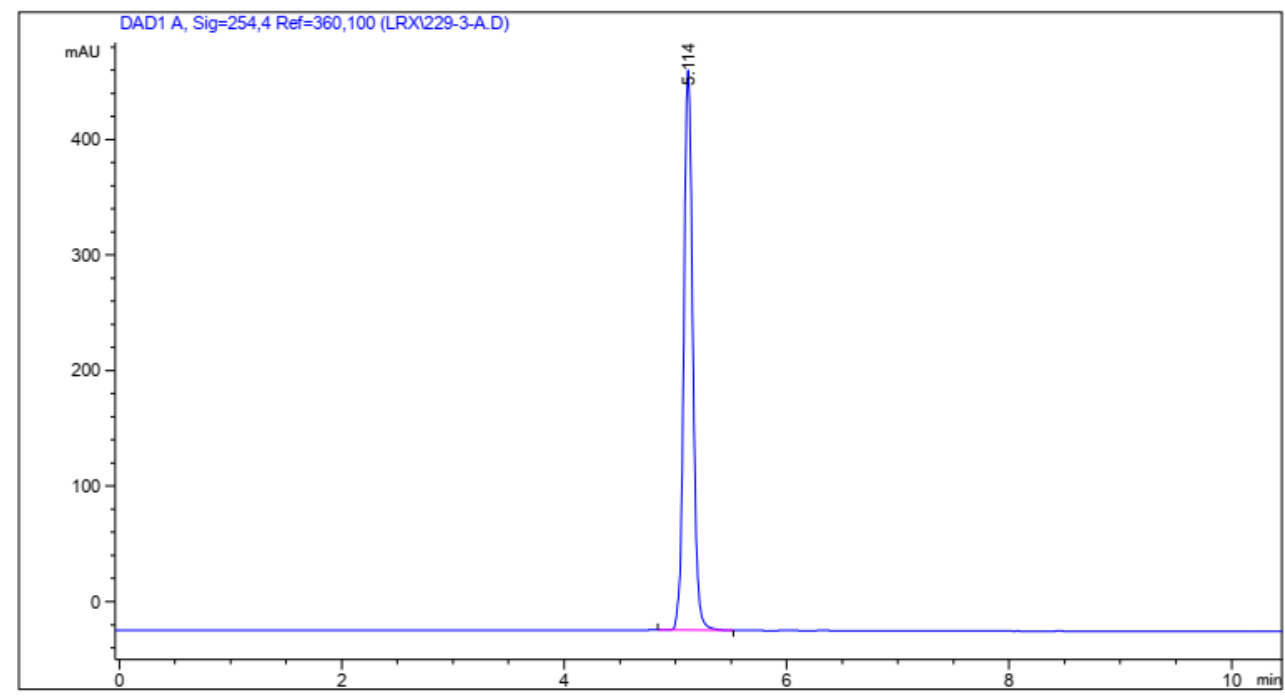

信号 1: DAD1 A, Sig=254,4 Ref $=360,100$

\begin{tabular}{|c|c|c|c|c|c|}
\hline $\begin{array}{r}\text { 峰 } \\
\#\end{array}$ & $\begin{array}{c}\text { 保留时间 类型 } \\
\text { [min] }\end{array}$ & $\begin{array}{l}\text { 峰晏 } \\
\text { [min] }\end{array}$ & $\begin{array}{r}\text { 峰面积 } \\
\text { [mAU*s] }\end{array}$ & $\begin{array}{r}\text { 峰高 } \\
\text { [mAU] }\end{array}$ & $\begin{array}{c}\text { 峰面积 } \\
\text { \% }\end{array}$ \\
\hline & - . & -1 & | & $\cdots$ & - \\
\hline 1 & 5.114 ВВ & 0.0875 & 2719.53101 & 484.66705 & 100.0000 \\
\hline 总量 & & & 2719.53101 & 484.66705 & \\
\hline
\end{tabular}

Compound 25

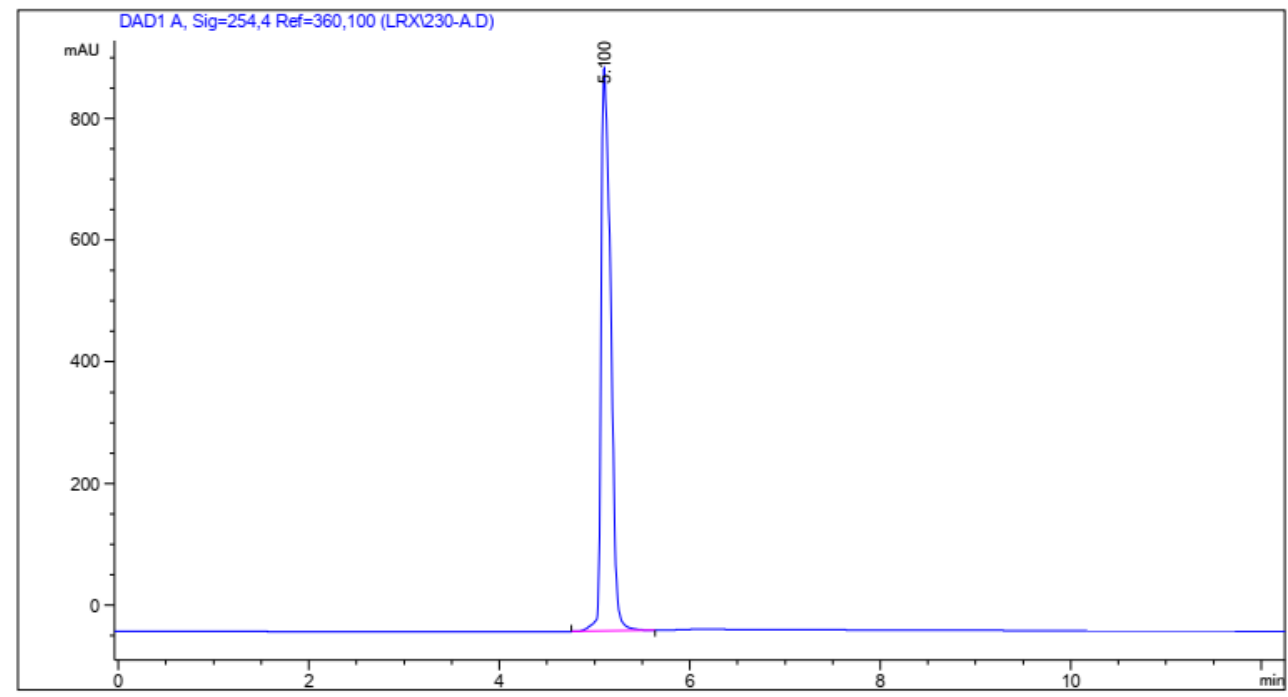

信号 1: DAD1 A, Sig=254,4 Ref $=360,100$

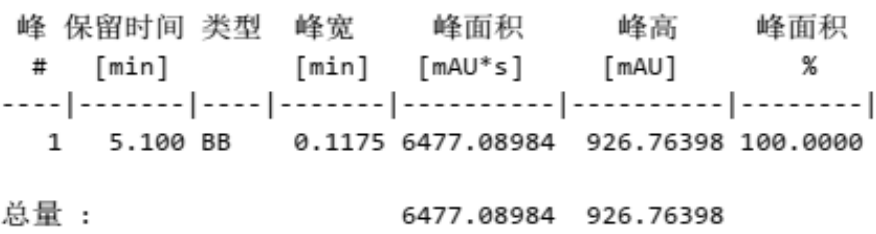


Compound 26

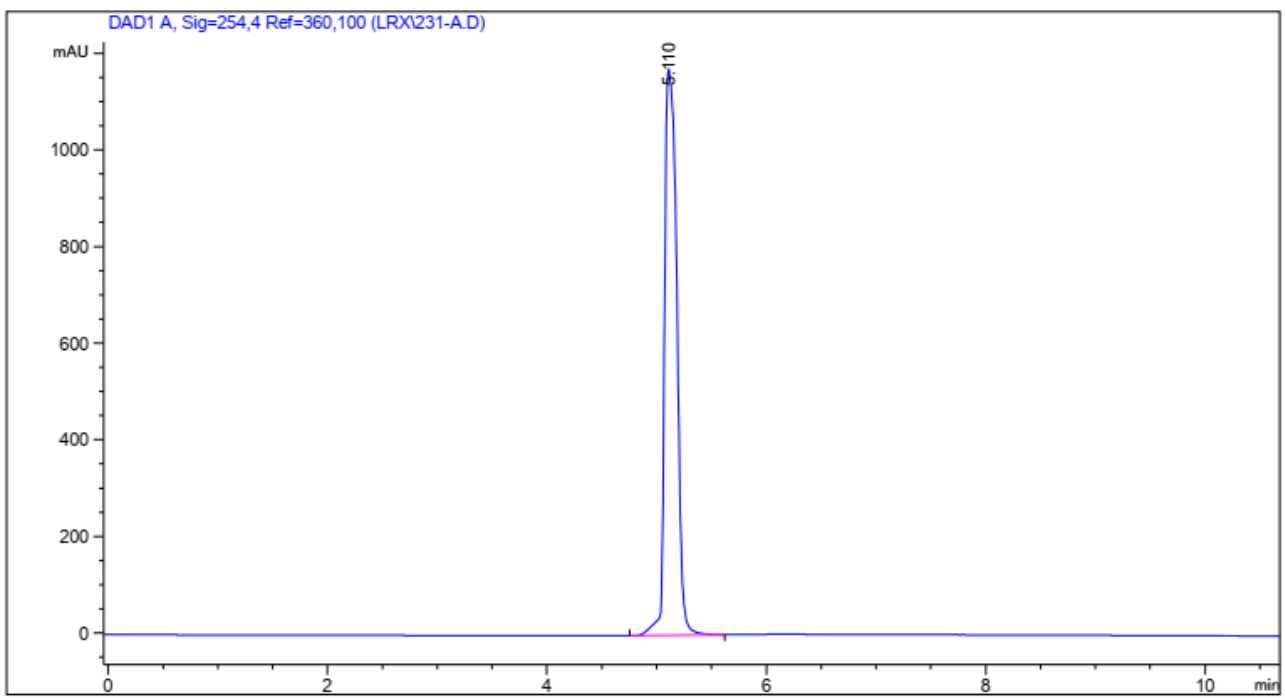

峰 保留时间 类型 峰宽峰面积 峰高 峰面积

$\begin{array}{lllll}\text { \# } & {[\mathrm{min}]} & {[\mathrm{min}]} & {[\mathrm{mAU} * \mathrm{~s}]} & {[\mathrm{mAU}]}\end{array}$

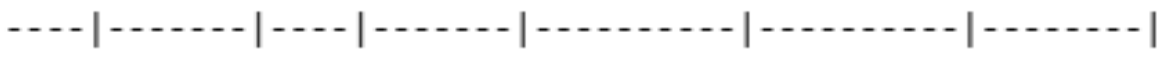

$1 \quad 5.110$ BB $\quad 0.12609027 .60547 \quad 1169.70117100 .0000$

总量：

9027.605471169 .70117

Compound 27

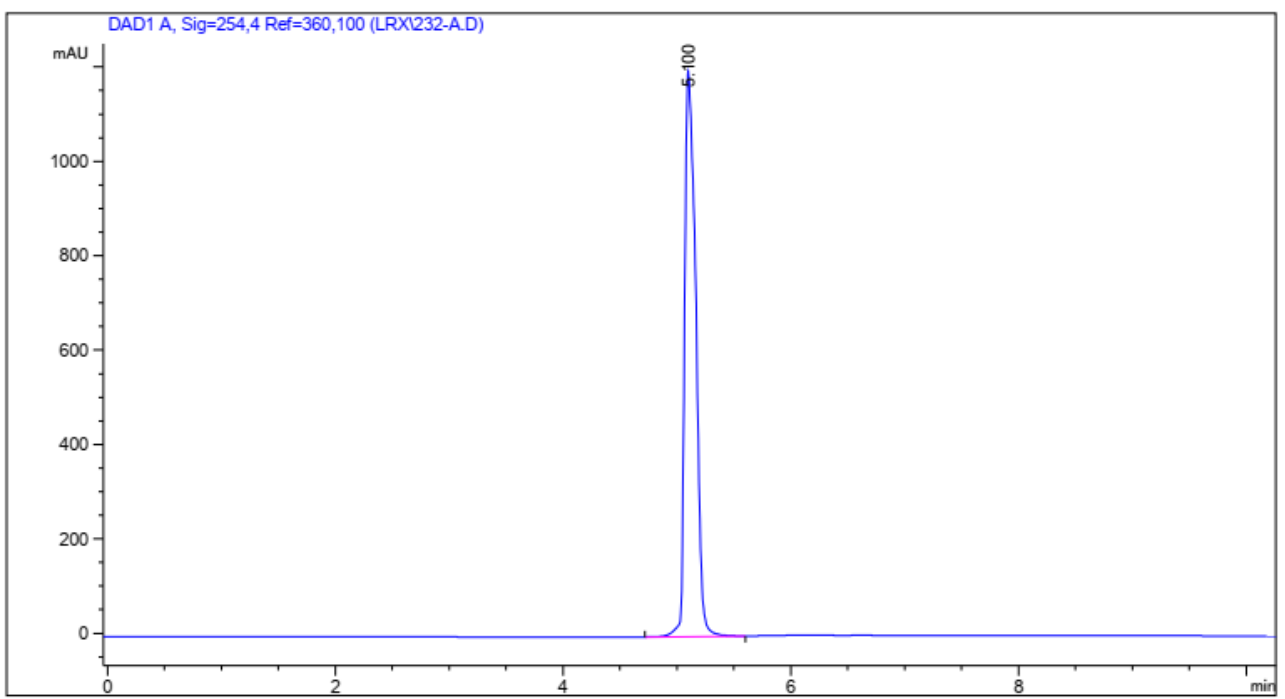

信号 1: DAD1 A, Sig=254,4 Ref $=360,100$

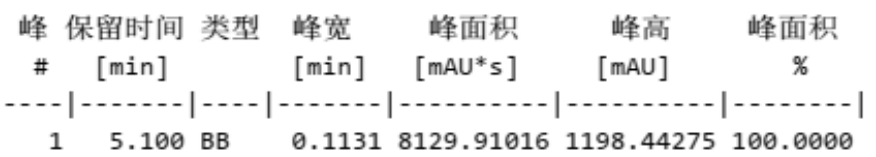

总量 :

8129.910161198 .44275 


\section{Compound 28}

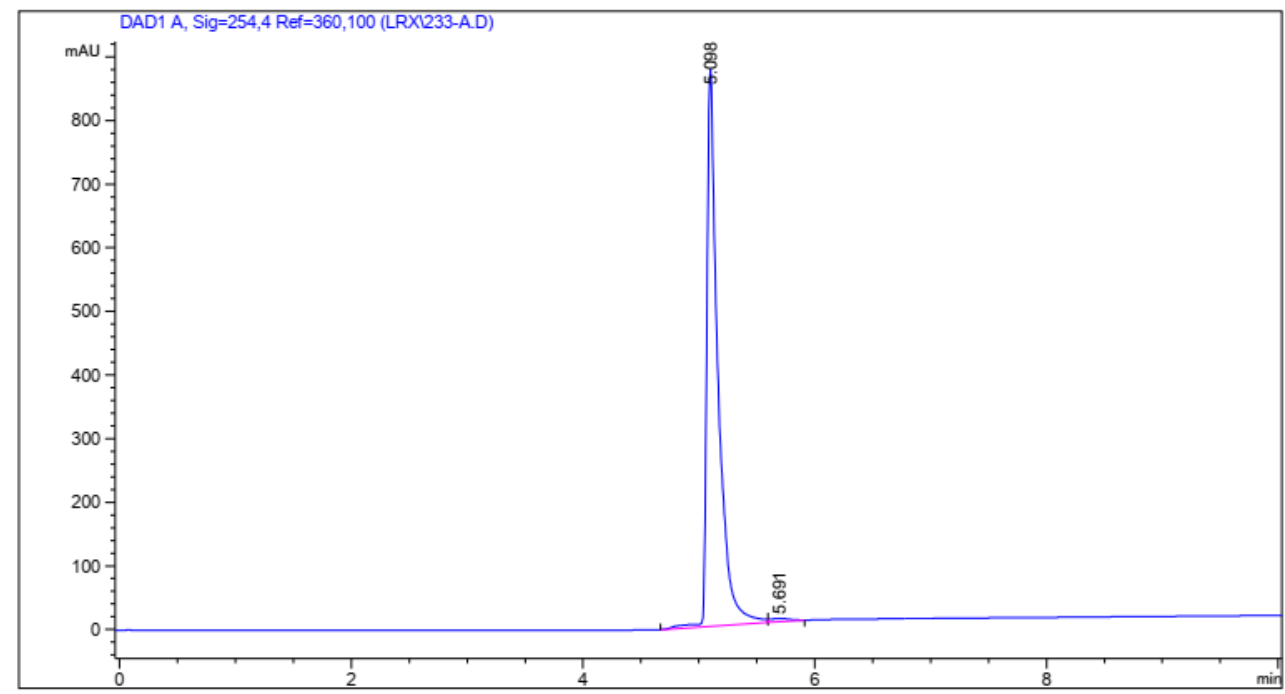

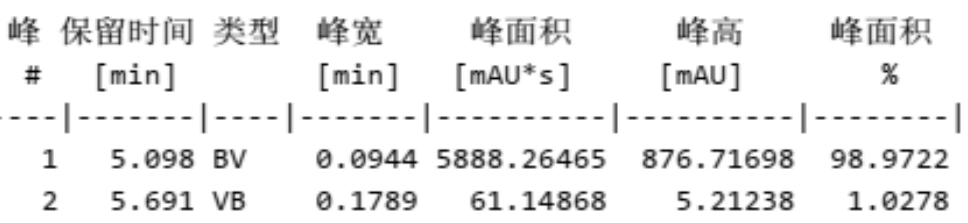

总量 :

$5949.41333 \quad 881.92936$

\section{Compound 29}

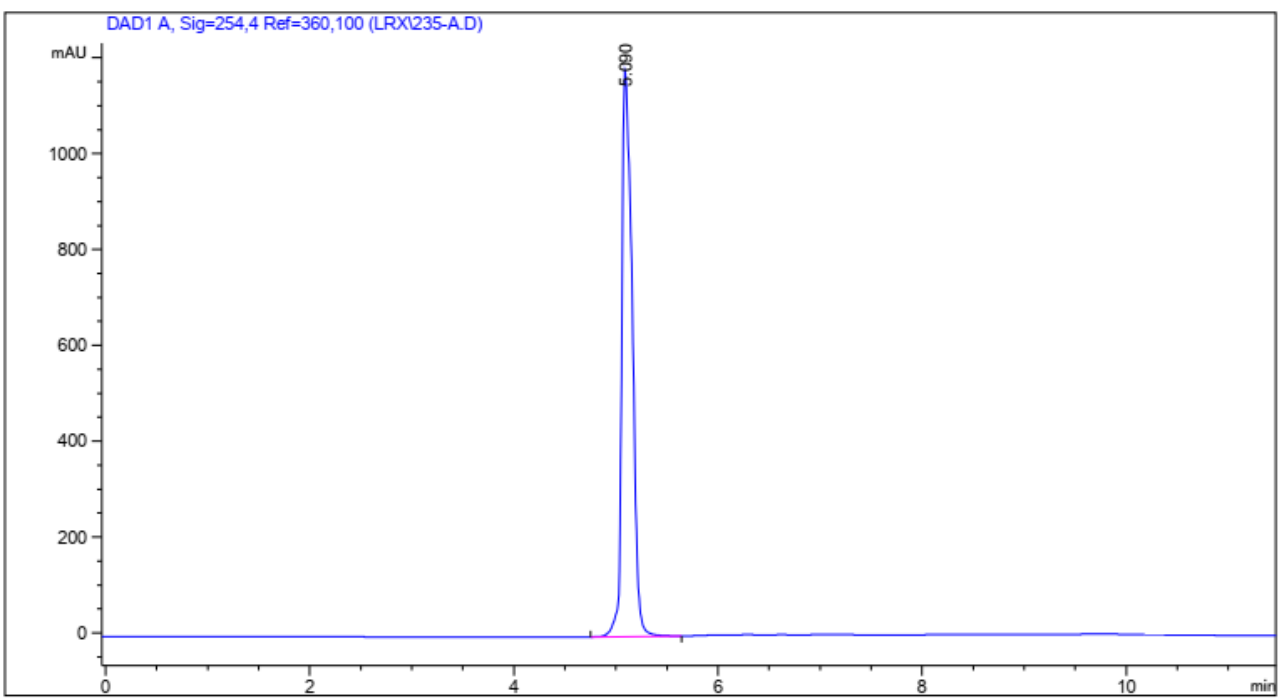

信号 1: DAD1 A, Sig=254,4 Ref $=360,100$

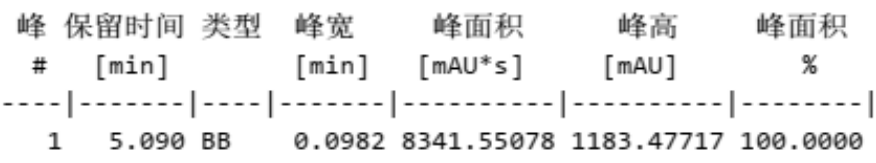

总量 :

$8341.55078 \quad 1183.47717$ 


\section{Compound $\mathbf{3 0}$}

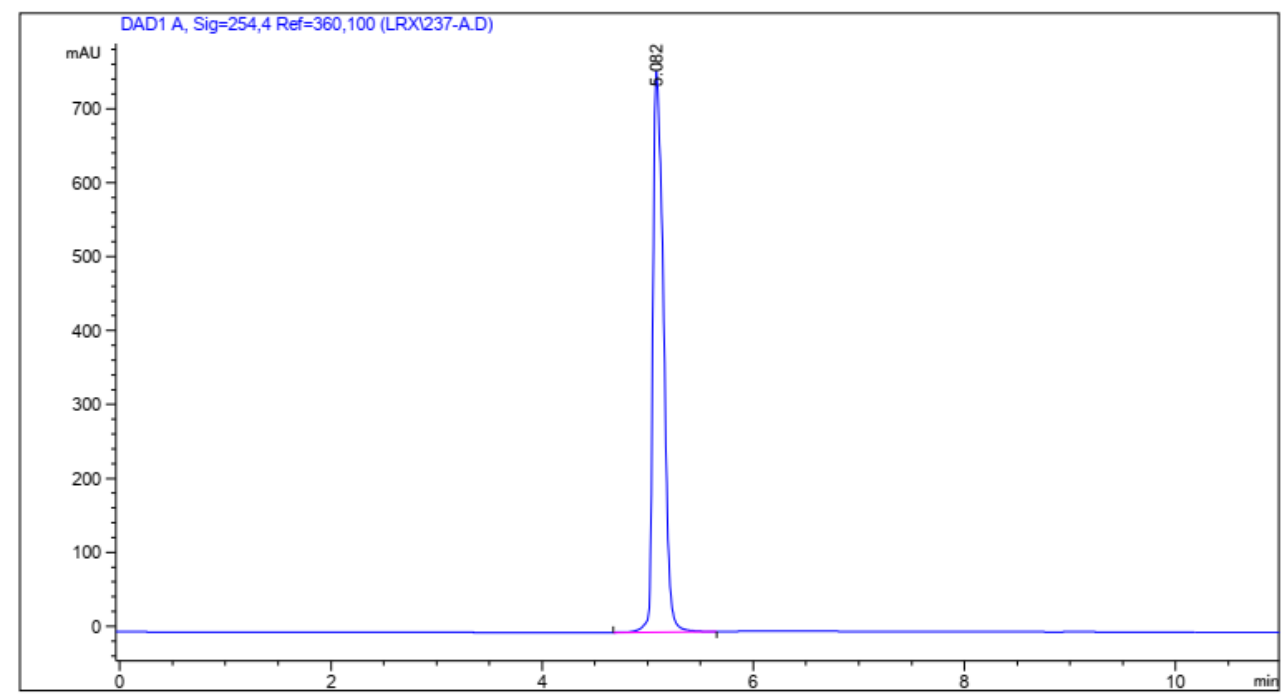

信号 1: DAD1 A, Sig $=254,4$ Ref $=360,100$

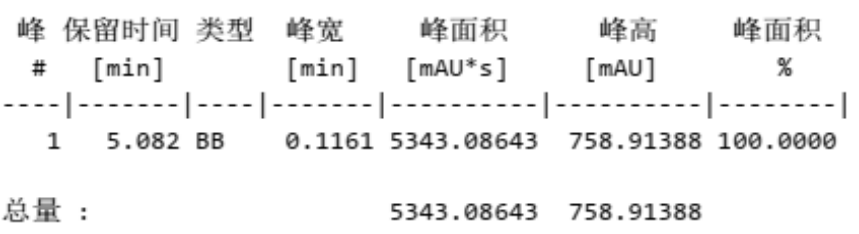

\section{Compound 31}

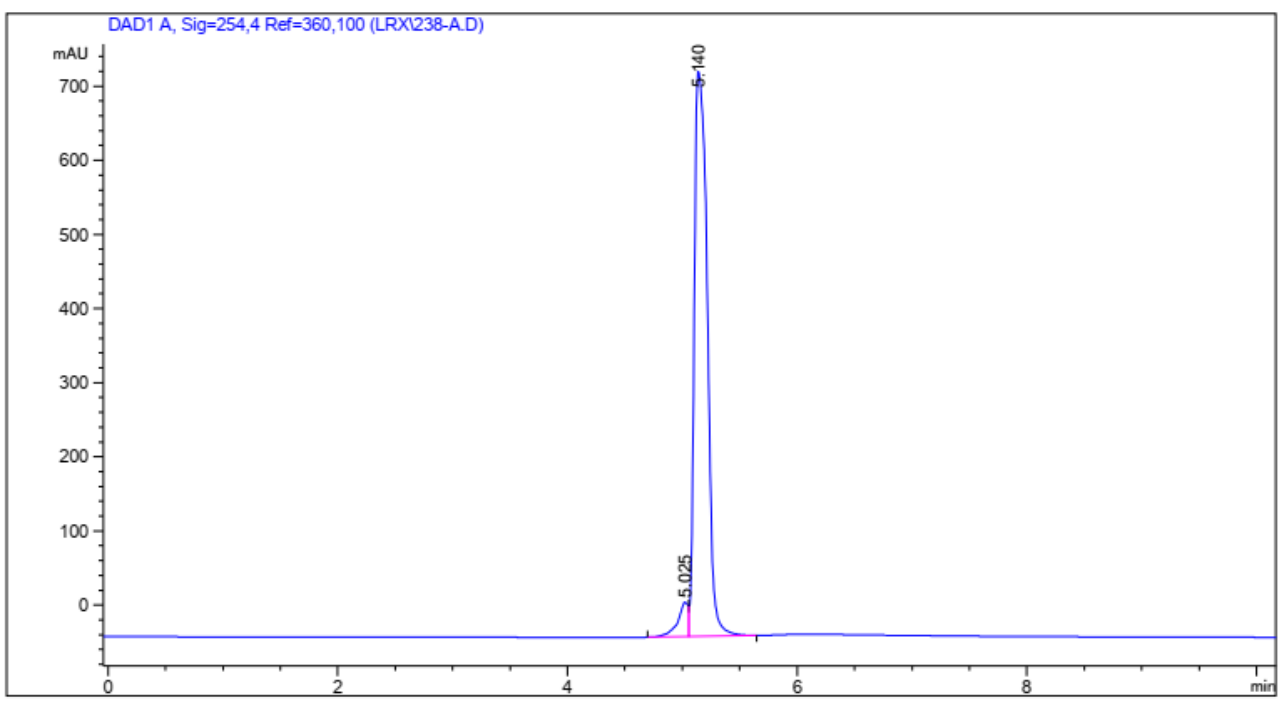

信号 1: DAD1 A, Sig $=254,4$ Ref $=360,100$

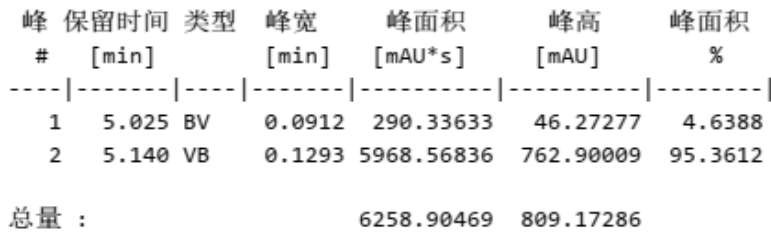




\section{Compound 32}

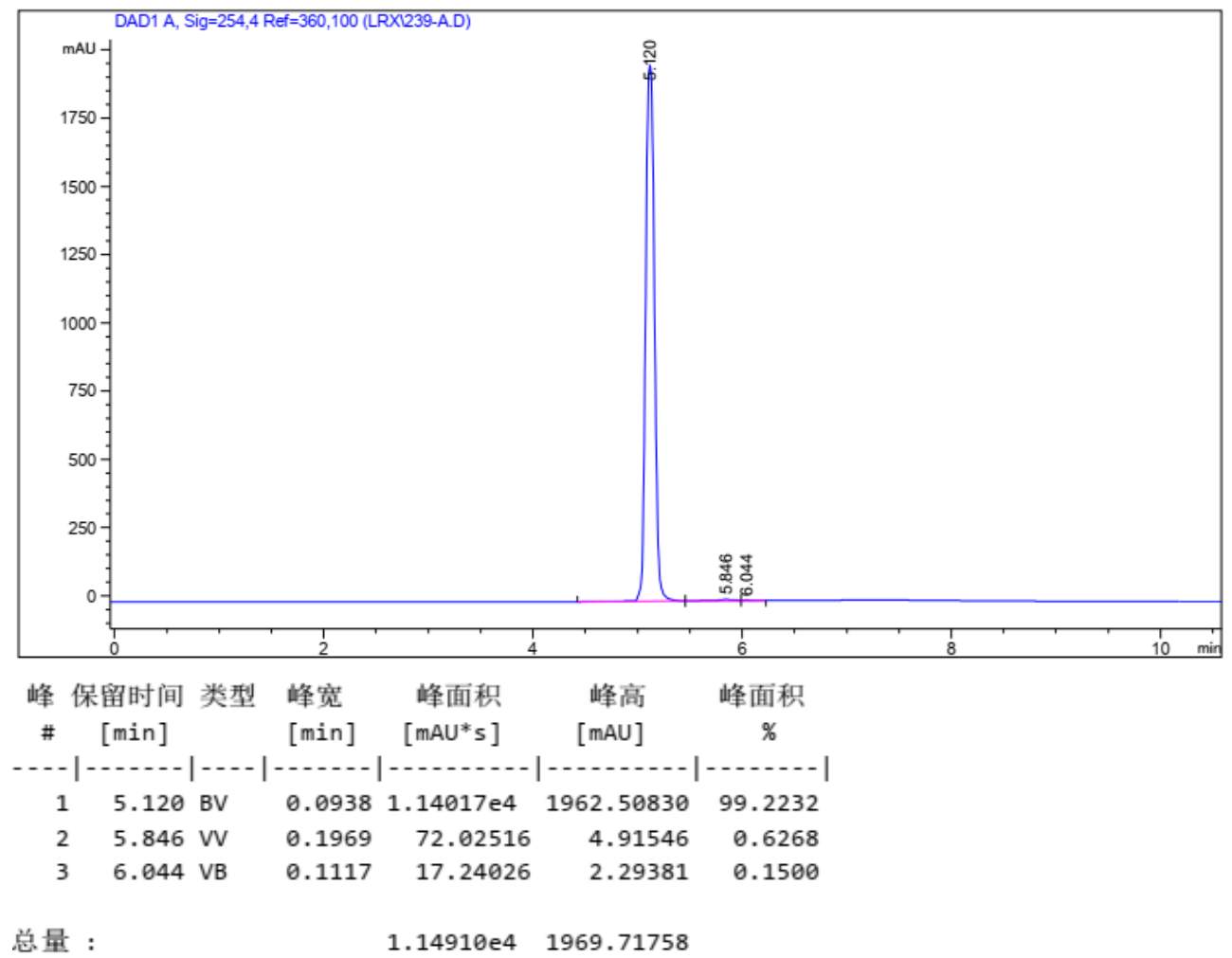

A

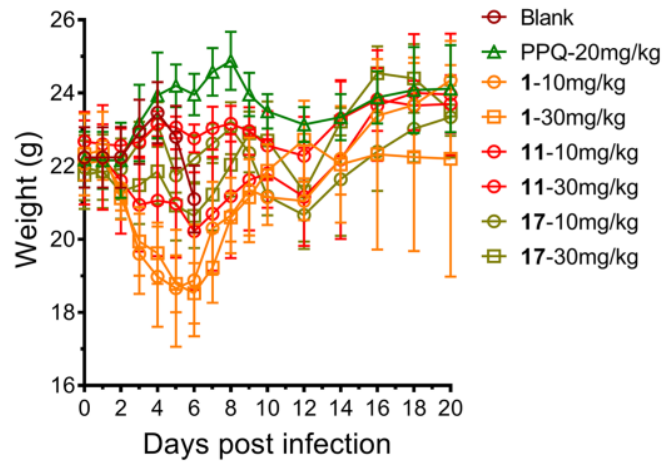

B

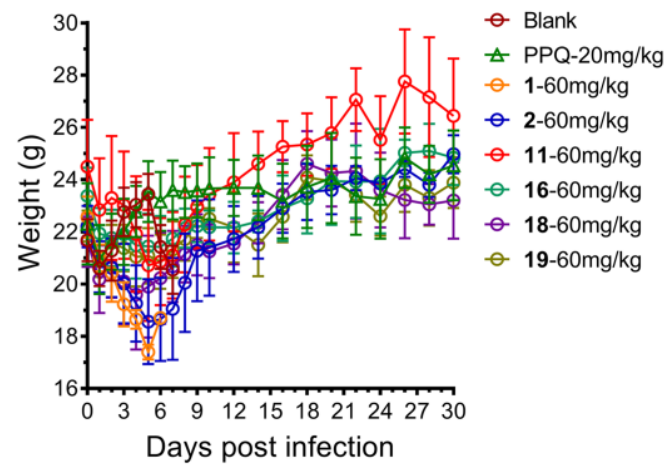

Figure. S1 Body weight date of in vivo erythrocytic antimalarial assay Data in (A) were corresponded to Figure 2A-B, and Data in (B) were corresponded to Figure 2C-D. All data were the mean \pm SD. 
A

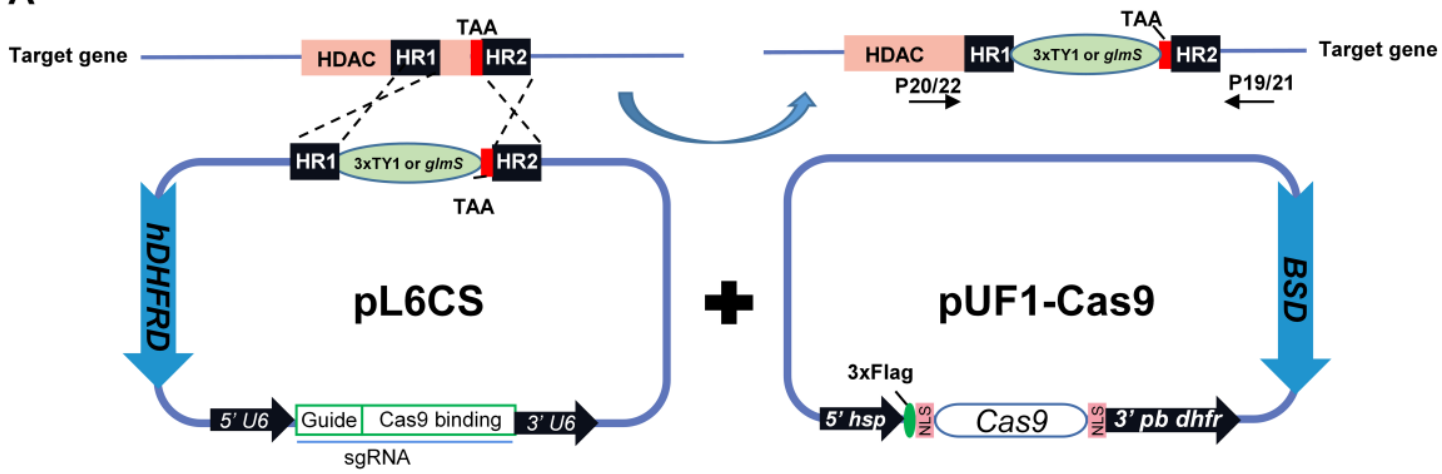

B

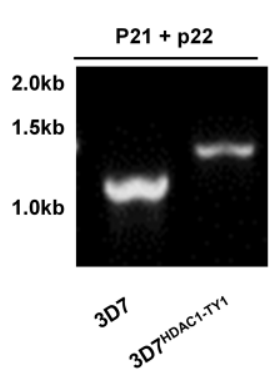

C

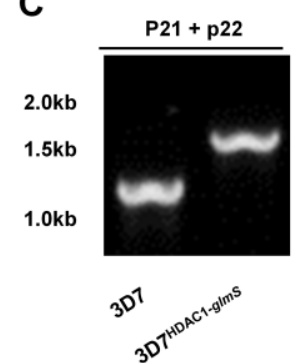

D

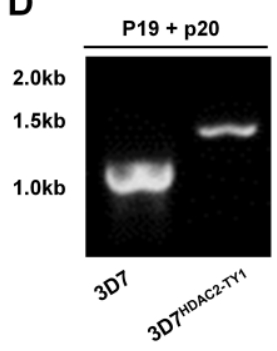

E

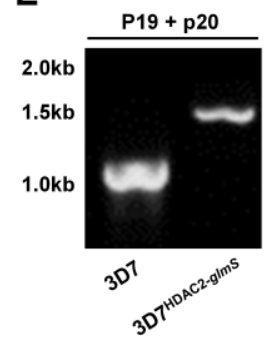

Figure. S2 Knock-down of PfHDAC1 and PfHDAC2. (A) Schematic of the gene conditional knock-down strategy by using the CRISPR/Cas9 system. HR1, the 5' flanking homologous recombinant fragment. HR2, the 3' flanking homologous recombinant fragment. $g \operatorname{lm} S$, ribozyme sequence used for the post transcriptional degradation of target genes induced by glucosamine $(\mathrm{GlcN}) .3 \times \mathrm{TY} 1$, a tag sequence used to detect the recombinant protein as experimental control. hDHFR, human dihydrofolate reductase. BSD, Blasticidin S Deaminase. P19/21 and p20/22, primer19, 20, 21 and 22 for PCR identification of gene editing. (B-E) PCR identification of 3D $7^{\mathrm{HDAC1} 1 \mathrm{TY} 1}(\mathrm{~B}), 3 \mathrm{D} 7^{\mathrm{HDAC1} 1-\mathrm{glmS}}(\mathrm{C}), 3 \mathrm{D} 7^{\mathrm{HDAC2}-\mathrm{TY} 1}(\mathrm{D})$, and 3D7 $7^{\mathrm{HDAC2}-\mathrm{glmS}}$ (E) gene editing. 

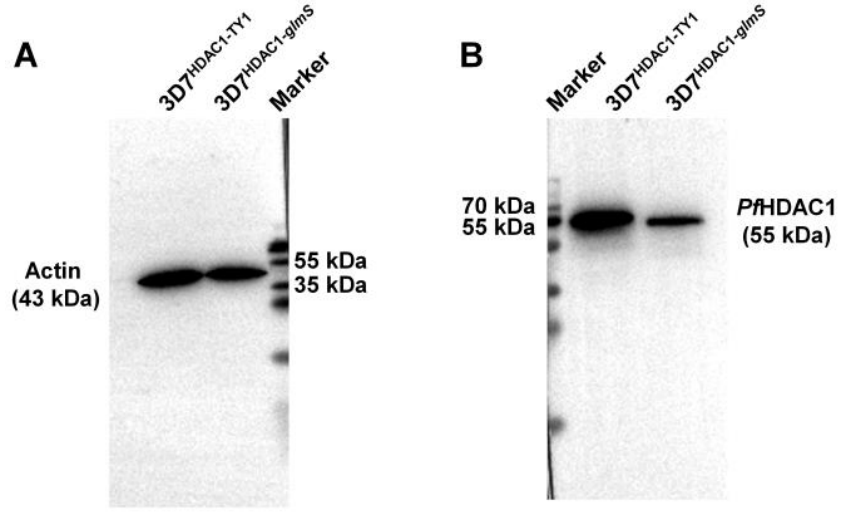

Figure. S3 Western Blot Identification of Knock-down of PfHDAC1. 3D7 ${ }^{\mathrm{HDAC1} \text { glmS }}$ and 3D7 ${ }^{\mathrm{HDAC1}-\mathrm{TY} 1}$ parasites were treatment with exogenous $\mathrm{GlcN}(2.5 \mathrm{mM})$ for $48 \mathrm{~h}$. Actin was selected as loading control.

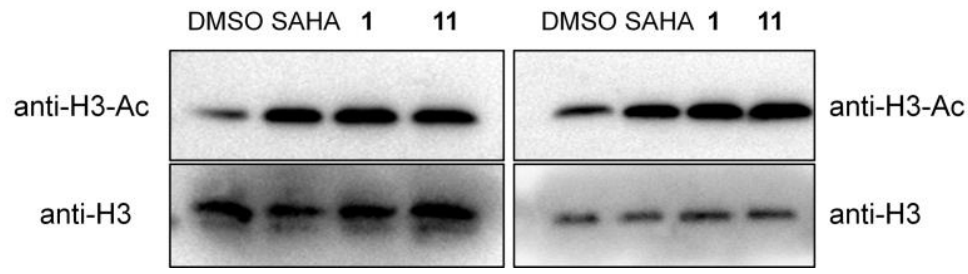

Figure S4. Repetitive Examination of Acetylation Level of P. falciparum Histone H3 by Treating with Compounds 1 and 11. The two independent repetitions of western blot assays in Figure 6. 
Table S2. Primers used in $P f H D A C 1 / 2$ gene knock-down study

\begin{tabular}{|c|c|}
\hline Primer name & Sequence \\
\hline \multicolumn{2}{|c|}{ Primers used in gene Knock down (5' to 3') } \\
\hline $\mathbf{P 1}$ & GCGGCCGCGCTAGCATTCCAGAAATTTATGAATTCGAAATTC \\
\hline $\mathbf{P 2}$ & GCGGCCCTAGTCTAGGGCGCGCCGTGGAATATAACAATTTCTTGAAAATAT \\
\hline P3 & TTTTTTTACAAAATGCTTAAGGGTAAAAGAAAATGATGTAAAAAAAC \\
\hline P4 & GCTAGCGCGGCCGCTAAACCAAATTTTAAAGCATCAAAAA \\
\hline P5 & GCGGCCGCGCTAGCATATGGTACAATAGATTGATCTCTGTCAGATAA \\
\hline P6 & GCGGCCCTAGTCTAGGGCGCGCCAATATACCTTTACTCGTTCTAGGTGGTG \\
\hline P7 & TTTTTTTACAAAATGCTTAAGGTTCCTACTTGGAACATATATATT \\
\hline P8 & GCTAGCGCGGCCGCGTGGAAAAATATATAACCAATGTG \\
\hline P9 & TTAAAATTTGGTTTCGCGGCCGCTTACTTGTCATCGTCATCCTTGT \\
\hline P10 & ATAAATTTCTGGAATGCTAGCGGAAGTGGTTCAGGTGGA \\
\hline P11 & TTAAAATTTGGTTTCGCATGCGTCCCCTCCTACATGTTTTTTG \\
\hline P12 & ATAAATTTCTGGAATGCTAGCGGCTCTGGCAGCGGCAGC \\
\hline P13 & TATATATTTTTCCACGCGGCCGCTTACTTGTCATCGTCATCCTTGT \\
\hline P14 & TCTATTGTACCATATGCTAGCGGAAGTGGTTCAGGTGGA \\
\hline P15 & TATATATTTTTCCACGCATGCGTCCCCTCCTACATGTTTTTTG \\
\hline P16 & TCTATTGTACCATATGCTAGCGGCTCTGGCAGCGGCAGC \\
\hline P17 & TAAGTATATAATATTTTTTTTTGATTTATCTGACAGTTTTAGAGCTAGAA \\
\hline P18 & TAAGTATATAATATTATTCATAAATTTCTGGAATTGTTTTAGAGCTAGAA \\
\hline P19 & AAATTATAAGAATATTAAAACGAATCGC \\
\hline $\mathbf{P 2 0}$ & ATAAATATGTTCGAACGTTATTTCTC \\
\hline $\mathbf{P 2 1}$ & TTATTTATTTACCAACTCAGAATGC \\
\hline $\mathbf{P 2 2}$ & ATCGATTGGGTAGATTTAATTTAAC \\
\hline \multicolumn{2}{|c|}{ Primers used in RT-qPCR (5' to 3') } \\
\hline PfHDAC2-FW & GTATGAAACCTAAAACACCTAC \\
\hline PfHDAC2-RV & AATCGTAAGGATTGTTGATTGC \\
\hline
\end{tabular}


PfHDAC1-FW CAAAGGAACATTCAACCACAC

PfHDAC1-RV GGTACAATAGATTGATCCCTG

S24 